\title{
Identifying the plasmapause in IMAGE EUV data using IMAGE RPI in situ steep density gradients
}

\author{
J. Goldstein, ${ }^{1}$ M. Spasojević, ${ }^{2}$ P. H. Reiff, ${ }^{1}$ B. R. Sandel, ${ }^{3}$ W. T. Forrester, ${ }^{3}$ \\ D. L. Gallagher, ${ }^{4}$ and B. W. Reinisch ${ }^{5}$ \\ Received 9 May 2002; revised 10 August 2002; accepted 29 January 2003; published 8 April 2003.
}

[1] Remote sensing of the entire plasmasphere is routinely accomplished by the Extreme Ultraviolet (EUV) imager on the IMAGE satellite. EUV observes the helium distribution in the plasmasphere by detecting resonantly scattered solar 30.4-nm ultraviolet radiation. In EUV images the plasmapause is assumed to be the " $\mathrm{He}^{+}$edge," i.e., the outermost sharp edge where the brightness of 30.4-nm $\mathrm{He}^{+}$emissions drops abruptly. This assumption is verified by comparing the $L$-shell of steep electron density gradients, extracted from passive mode dynamic spectrograms recorded by the IMAGE Radio Plasma Imager (RPI) when the satellite is at low magnetic latitude, with the $L$-shell of EUV He ${ }^{+}$edges obtained when the satellite is outside the plasmasphere near apogee. A statistical study of all inbound (dawn sector) plasmapause crossings was performed for the month of June 2001. When the plasmapause location observed by RPI is compared to the location of the $\mathrm{He}^{+}$edge extracted from the closest-in-time EUV image, a correlation coefficient of 0.83 is obtained. When the EUV $\mathrm{He}^{+}$edge location is taken as the average of two EUV measurements (one before and one after the RPI measurement), the correlation coefficient increases to 0.87 . The high degree of correlation justifies the assumption that the $\mathrm{He}^{+}$edge coincides with the plasmapause. For eighteen cases in which the plasmasphere has no sharp outer boundary the intensity of the uncalibrated EUV images is compared with the electron number density extracted from the RPI data, and the lower sensitivity threshold of the EUV instrument is estimated to be $40 \pm 10$ electrons $\mathrm{cm}^{-3}$. INDEX TERMS: 2768 Magnetospheric Physics:

Plasmasphere; 2730 Magnetospheric Physics: Magnetosphere—inner; 2740 Magnetospheric Physics:

Magnetospheric configuration and dynamics; 2794 Magnetospheric Physics: Instruments and techniques;

KEYWORDS: plasmasphere, plasmapause, inner magnetosphere, remote sensing, imaging

Citation: Goldstein, J., M. Spasojević, P. H. Reiff, B. R. Sandel, W. T. Forrester, D. L. Gallagher, and B. W. Reinisch, Identifying the plasmapause in IMAGE EUV data using IMAGE RPI in situ steep density gradients, J. Geophys. Res., 108(A4), 1147, doi:10.1029/2002JA009475, 2003.

\section{Introduction}

[2] The plasmasphere is the torus of cold (about $1 \mathrm{eV}$ ), dense (electron density of the order of $100-10,000 \mathrm{~cm}^{-3}$ ) plasma that encircles the Earth. Nishida [1966] and Brice [1967] proposed the following simple quasi-stationary picture of plasmaspheric dynamics. Near the Earth and at low latitudes, magnetic flux tubes follow drift paths that corotate with the Earth and therefore have the opportunity to be filled with escaping ionospheric plasma over a period of a

\footnotetext{
${ }^{1}$ Department of Physics and Astronomy, Rice University, Houston, Texas, USA.

${ }^{2}$ STAR Lab, Stanford University, Stanford, California, USA.

${ }^{3}$ Lunar and Planetary Laboratory, University of Arizona, Tucson, Arizona, USA.

${ }^{4}$ National Space Science and Technology Center, NASA Marshall Space Flight Center, Huntsville, Alabama, USA.

${ }^{5}$ Center for Atmospheric Research, University of Massachusetts, Lowell, Massachusetts, USA.
}

Copyright 2003 by the American Geophysical Union. 0148-0227/03/2002JA009475\$09.00 few to several days. Outside of a separatrix sometimes called the "last closed equipotential" (LCE), flux tubes participate in the (globally sunward) magnetospheric convection and interact with the ionosphere on a much shorter time scale. As these convecting flux tubes experience only minimal ionospheric filling, number densities outside the LCE are much lower $\left(0.1-10 \mathrm{~cm}^{-3}\right)$. In the quasi-stationary picture the LCE is assumed to coincide with the plasmapause (i.e, the boundary between the high-density inner region and the low-density outer region).

[3] The plasmapause is often manifested as a transition between densities of the order of $10-100 \mathrm{~cm}^{-3}$ and $100-$ $1000 \mathrm{~cm}^{-3}$. First discovered in ground-based whistler wave measurements [Carpenter, 1963] and early satellite observations [Gringauz, 1963], the plasmapause density gradient can be quite steep, exhibiting a drop of two orders of magnitude in less than one Earth radius $\left(R_{\mathrm{E}}\right)$ of altitude. The outer plasmasphere and plasmapause region can have a great deal of structure, including MHD turbulence, quasiperiodic density variations with peak-to-valley density ratios of 2 or more, and deep, factor-5-or-more, density 
cavities [e.g., LeDocq et al., 1994; Moldwin et al., 1995; Carpenter and Lemaire, 1997, and references therein; Carpenter et al., 2000]. The plasmapause density profile may include multiple gradients or can have a gradually decreasing density profile with no clear plasmapause boundary [Horwitz et al., 1990a]. For various reasons, including the inherently unsteady and spatially structured nature of magnetospheric convection and the various time scales on which the plasmasphere responds to the forces of erosion and refilling, the depiction of the plasmapause as the LCE is an oversimplification. In reality, the LCE and the plasmapause rarely coincide, and the LCE concept does not provide a sufficiently detailed explanation of the evolving states of the plasmasphere. [e.g., Carpenter, 1995; Lemaire, 2001].

[4] The dominant plasmaspheric ion species is $\mathrm{H}^{+}$; at $L \approx$ 3 , hydrogren number density $N_{\mathrm{H}^{+}}$is (on average) about $1000 \mathrm{~cm}^{-3}$, roughly $80 \%$ of the total ion number density. The plasmasphere contains significant amounts of $\mathrm{He}^{+}$and $\mathrm{O}^{+}$as well (typically, $\mathrm{He}^{+} / \mathrm{H}^{+}$is $0.1-0.2$ and $\mathrm{O}^{+} / \mathrm{H}^{+}$is 0.05-0.1 [Comfort et al., 1988; Craven et al., 1997]). Although the dominant ion $\mathrm{H}^{+}$has no optical emissions, extreme ultraviolet (euv) light emitted from $\mathrm{He}^{+}$(and possibly $\mathrm{O}^{+}$) can be used for remote sensing the plasmasphere. This technique was shown to be feasible [Weller and Meier, 1974; Meier and Weller, 1974; Chakrabarti et al., 1982; Swift et al., 1989] and utilized to produce preliminary global images of portions of the plasmasphere in $30.4 \mathrm{~nm}$ light [Meier et al., 1998; Nakamura et al., 2000].

[5] The Extreme Ultraviolet (EUV) instrument on the IMAGE satellite [Burch, 2000] is the first instrument to provide full global images of the plasmasphere on a routine basis [Sandel et al., 2000, 2001]. EUV detects resonantly scattered solar 30.4-nm radiation and produces images with $0.1 R_{\mathrm{E}}$ spatial resolution (or better) every $10 \mathrm{~min}$, allowing detailed observation of a number of mesoscale (less than $1 R_{\mathrm{E}}$ in size) plasmaspheric features such as convection tails, "bite-outs" (or "plasma voids"), "fingers," and "shoulders" [Sandel et al., 2001; Burch et al., 2001a, 2001b; Goldstein et al., 2002]. Two basic assumptions used in the interpretation of EUV images are (1) that the intensity of $30.4-\mathrm{nm}$ light is proportional to the $\mathrm{He}^{+}$ number density, integrated along the line of sight of EUV's cameras and (2) that the $\mathrm{He}^{+}$population (as seen by EUV) can be used as a qualitative proxy for the entire plasmasphere. Because the plasmasphere is optically thin to 30.4$\mathrm{nm}$ radiation [Sandel et al., 2000, 2001], assumption (1) should be valid. The investigation of assumption (2) is the basis of this paper. Specifically, we show that when the plasmapause is sharp (i.e., when it is characterized by a steep density gradient), it can be reliably associated with an easily identifiable feature in EUV images. That feature, henceforth called the "He ${ }^{+}$edge," is defined as the outermost sharp edge where the intensity of detected 30.4-nm radiation (from $\mathrm{He}^{+}$) drops abruptly. (An example of the $\mathrm{He}^{+}$edge is shown in the EUV image of Figure 2a in section 2.)

[6] Given assumption (1), the $\mathrm{He}^{+}$edge should indeed be a good proxy for the plasmapause, unless the ratio $\alpha \equiv$ $N_{\mathrm{He}^{+}} / N_{\mathrm{H}^{+}}$varies significantly (e.g., nonmonotonically) in the plasmasphere. Statistical studies [Lennartsson and Sharp,
1982; Comfort et al., 1988; Craven et al., 1997] indicate that $\alpha$ does vary both spatially $\left(\log _{10} \alpha\right.$ can be characterized by a linear decrease with $L$-shell or radial geocentric distance) and dynamically (increasing during geomagnetic activity). However, these studies imply that $\alpha$ does not vary in such a way as to produce distinct plasmapause locations for each ion species. Case studies of $\mathrm{He}^{+}$and $\mathrm{H}^{+}$measurements, e.g., Horwitz et al. [1984, 1990b], show that $\mathrm{He}^{+}$and $\mathrm{H}^{+}$are highly correlated. In particular, when the $\mathrm{H}^{+}$profile exhibits a steep density gradient (such as at the plasmapause), the $\mathrm{He}^{+}$profile does as well. Based on observational evidence therefore the plasmapause should not be expected to differ in location as one goes from $\mathrm{H}^{+}$to $\mathrm{He}^{+}$.

[7] A quantitative test is made possible by measurements of the Radio Plasma Imager (RPI), also on board the IMAGE satellite. RPI has the capability to perform both active and passive sounding [Reinisch et al., 2000]. The instrument's two perpendicular spin-plane wire antennas were deployed to an unprecedented length $(500 \mathrm{~m}$, tip-totip), making RPI sensitive from $3 \mathrm{MHz}$ down to $3 \mathrm{kHz}$. First results from RPI [Reinisch et al., 2001] highlight some of the active sounding capabilities. This paper will utilize RPI passive measurements of the local plasma wave environment, which provide in situ determinations of the electron density.

[8] The ability to clearly interpret the EUV images will allow observation, from a global perspective, of the important interaction between the plasmasphere and the larger magnetosphere. Because the plasmapause migrates in response to changes in the strength of magnetospheric convection (e.g., stronger convection leads to a "shrinking" of the plasmasphere as the plasmapause moves radially inward), the location of the plasmapause (along with indices such as $K_{\mathrm{p}}$ and $D_{\mathrm{st}}$ ) provides an indicator of the strength of geomagnetic activity. Burch et al. [2001b] speculated that the dynamic location of the plasmapause can be used to deduce a global map of the convection electric field. There are indications that the plasmapause may participate in precipitation/loss of the ring current [Burch et al., 2001a], the hotter plasma population that resides just outside the plasmasphere. Although the density structure of the plasmasphere has been investigated via measurements on previous satellites, much about it remains poorly known, especially its behavior on various spatial scales during cycles of erosion and recovery [Carpenter and Lemaire, 1997]. Thus the unambiguous identification of the plasmapause in EUV images is essential.

\section{EUV and RPI Data}

\subsection{IMAGE Orbit}

[9] Figure 1 is a schematic diagram of the orbit of the IMAGE satellite during June 2001. During this month the orbit plane was oriented roughly along the dawn-dusk magnetic meridional plane. Apogee (marked "a") was 8.2 $R_{\mathrm{E}}$ and perigee (" $\mathrm{p}$ ") was $1.2 R_{\mathrm{E}}$. In Figure 1 the direction of travel of IMAGE is indicated by the arrow and by labeled points. Thus in the figure, IMAGE cycles through (in order) points 1-2-p-3-4-a, repeating this sequence every 14.2 -hour orbit. Traveling along the path 2-p-3, IMAGE successively passes through two lobes of the plasmasphere (labeled " $\mathrm{A}$ " and "B" in Figure 1). The number/letter scheme (for points 


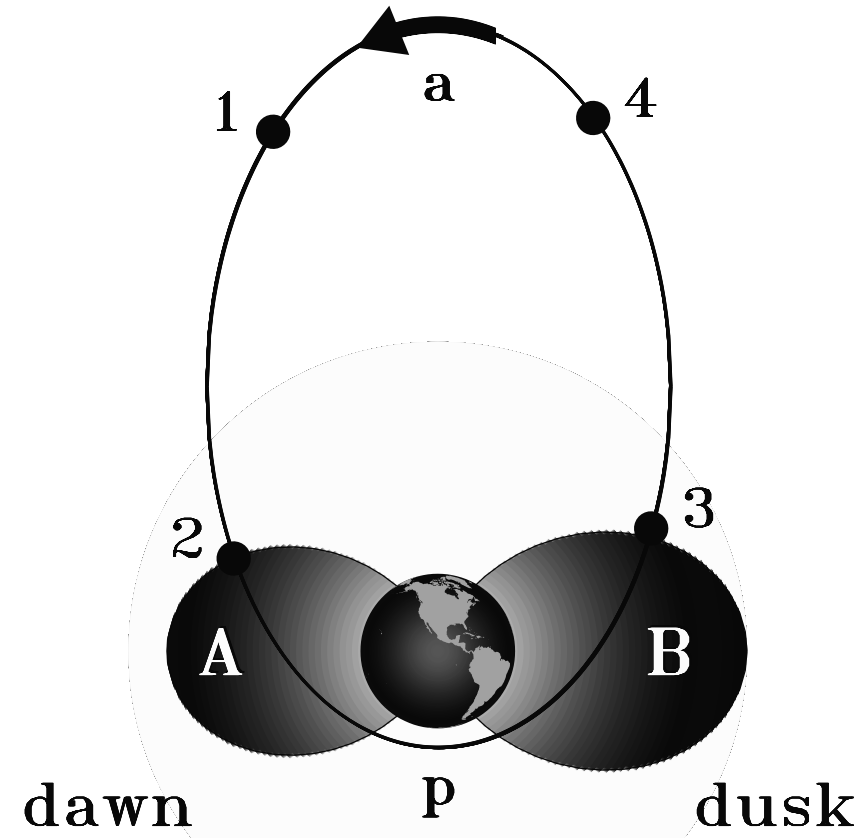

Figure 1. Schematic IMAGE orbit for June 2001. IMAGE orbits in the direction of the arrow. EUV remote-sensing images are taken between points 4 and 1, and RPI infers in situ plasmaspheric number density between points 2 and 3 as it passes through plasmaspheric lobes A and B. Points "a" and "p" are apogee and perigee, respectively.

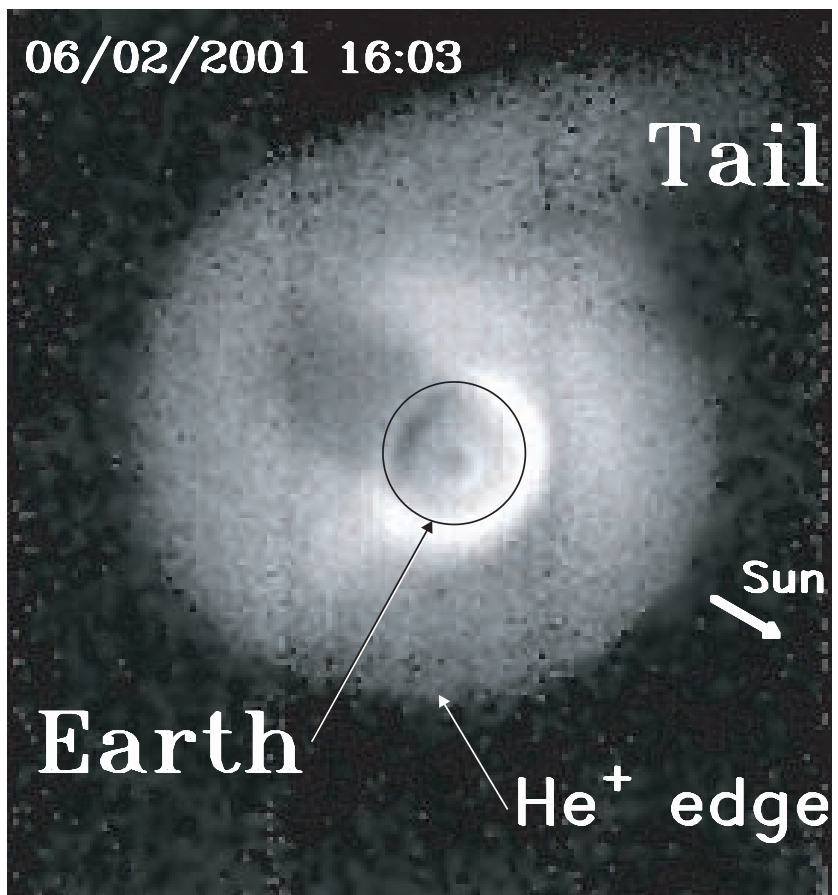

Figure 2a. Image of the $\mathrm{He}^{+}$plasmasphere taken by EUV, 1603 UT on 2 June 2001. The plasmasphere, exhibiting a dusk-sector drainage tail, is the bright region surrounding the Earth. It is assumed that the plasmapause coincides with the " $\mathrm{He}^{+}$edge." along the orbit) introduced here will be employed throughout the paper.

\subsection{EUV Data}

[10] While IMAGE is near apogee " $a$," traveling along the orbit segment between 4 and 1, the EUV instrument looks down to the equatorial plane and obtains remote-sensing images of the plasmasphere. Each frame of EUV data is an accumulation of 30.4-nm light from five spins of the IMAGE satellite; frames are produced at a rate of $1 /(10 \mathrm{~min})$. (See further description in section 5.) An example of an EUV image from 2 June 2001 is shown in Figure 2a. In the image the view is from above the north pole; the Earth's apparent size and location are indicated by the black circle in the center. The Sun is to the lower right in the direction of the thick white arrow; the dayside limb of the Earth exhibits a bright arc that contains 58.4-nm neutral helium "airglow." The shadow of the Earth is faintly visible, extending away from the Earth toward the upper left. The light haze around the Earth, forming an oval roughly $8 R_{\mathrm{E}}$ in diameter, is the $\mathrm{He}^{+}$portion of the plasmasphere, glowing in 30.4-nm ultraviolet light. A "tail" of plasma extends up and to the right from the duskside plasmasphere. This tail is presumably composed of plasma that is being drained from the plasmasphere by sunward magnetospheric convection. The $\mathrm{He}^{+}$ emissions drop sharply about $3-5 R_{\mathrm{E}}$ out (depending on the local time) from the center of the diagram, at the feature labeled the " $\mathrm{He}^{+}$edge." It has so far been assumed that this $\mathrm{He}^{+}$edge is the plasmapause (e.g., Burch et al. [2001b]).

[11] In Figure $2 \mathrm{~b}$ the $\mathrm{He}^{+}$edge of Figure $2 \mathrm{a}$ has been manually extracted and mapped down to the magnetic equatorial plane with the aid of a cursor-based software routine that works as follows. (1) Points are selected along the $\mathrm{He}^{+}$edge in an EUV image. (2) Assuming a dipole

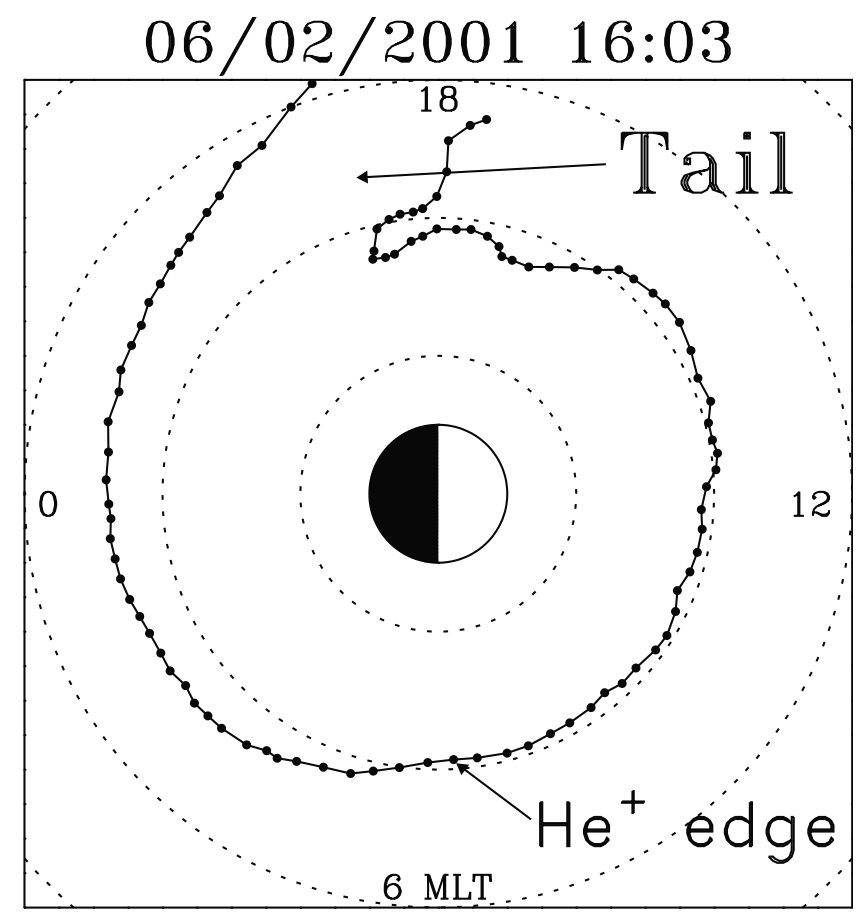

Figure 2b. The $\mathrm{He}^{+}$edge from the EUV image of Figure $2 \mathrm{a}$ has been mapped down to the magnetic equatorial plane. Noon MLT is to the right. 


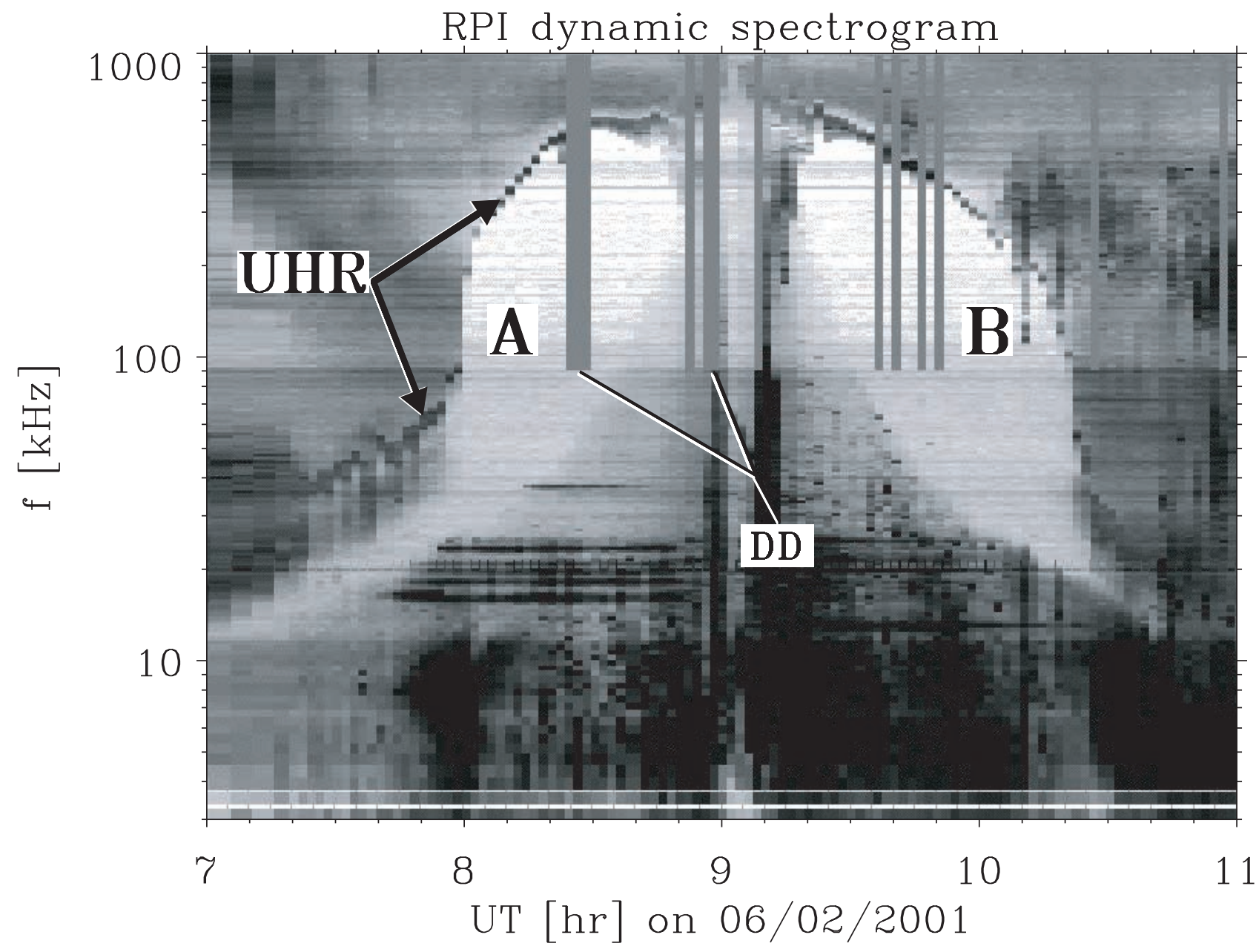

Figure 3a. RPI dynamic spectrogram, showing the in situ plasma wave environment of IMAGE from 0700-1100 UT on 2 June. The upper and lower edges of the upper hybrid resonance (UHR) noise band are $f_{\text {uh }}$ (the UHR frequency) and $f_{\text {pe }}$ (the plasma frequency), respectively. ("DD" = data dropout.)

magnetic field, the mapping software finds the field line with the minimum $L$ (radial distance in the equatorial plane) value along the line of sight to each selected point. (3) The software assumes that the $\mathrm{He}^{+}$edge is aligned with this field line, and assigns $L$ and MLT values for each point. In this way, perspective distortion (due to distance and view angle) in the EUV image can be effectively removed for the $\mathrm{He}^{+}$ edge. There is some subjectivity involved in manually extracting the $\mathrm{He}^{+}$edge. Where the $\mathrm{He}^{+}$edge is sharp (as in the lower half of the image in Figure 2a), the uncertainty due to subjectivity is estimated to be two pixels, about $0.2 R_{\mathrm{E}}$. For diffuse structures like the tail the uncertainty is about $4-8$ pixels $\left(0.4-0.8 R_{\mathrm{E}}\right)$. Noise in the images comes from scattered sunlight, which varies with observing geometry, and from direct particle excitation, which varies with geomagnetic activity. It should be mentioned that the image reproduced in printed form in Figure $2 \mathrm{a}$ is lower quality than the (electronic) image used by the mapping software. In particular, the drainage tail is harder to see in the printed image than in the electronic image.

\subsection{RPI Data}

[12] Throughout the orbit depicted in Figure 1, RPI obtains in situ passive plasma wave measurements. In parts of the orbit where the electron plasma frequency $f_{\mathrm{pe}}$ is greater than the electron cyclotron frequency $f_{\text {ce }}$, a typical feature of passive plasma wave spectra is the upper hybrid resonance (UHR) noise band. The UHR noise signature is a local enhancement in signal intensity that occurs between $f_{\mathrm{pe}}$ and the UHR frequency $f_{\mathrm{uh}} \equiv \sqrt{f_{\mathrm{pe}}^{2}+f_{\mathrm{ce}}^{2}}$ [Mosier et al., 1973; Carpenter et al., 1981]. The UHR frequency is measured as the upper edge of the noise band and converted to a number density $n_{\mathrm{e}}$ using $n_{\mathrm{e}}\left[\mathrm{cm}^{-3}\right] \approx\left(f_{\mathrm{uh}}^{2}-f_{\mathrm{ce}}^{2}\right) /(8.98$ $\mathrm{kHz})^{2}$. Since IMAGE does not carry a science magnetometer, $f_{\text {ce }}$ is estimated using the Tsy96-1 magnetic field model [Tsyganenko and Stern, 1996], carrying an uncertainty that is a few percent during quiet times and an order of magnitude above that during storm periods. In some cases it is possible to get $f_{\text {pe }}$ directly from the lower edge of the noise band, avoiding the necessity of using a magnetic field model. A sample RPI dynamic spectrogram from 0700-1100 UT on 2 June 2001 is shown in Figure $3 \mathrm{a}$. Wave intensity is indicated by the grayscale; black is most intense, and white is least intense. The dark trace rising from about $40 \mathrm{kHz}$ at $0730 \mathrm{UT}$ is the UHR noise band (labeled "UHR"). Moving from left to right across the spectrogram, the noise band can be followed visually to yield the qualitative shape and size of the plasmasphere 


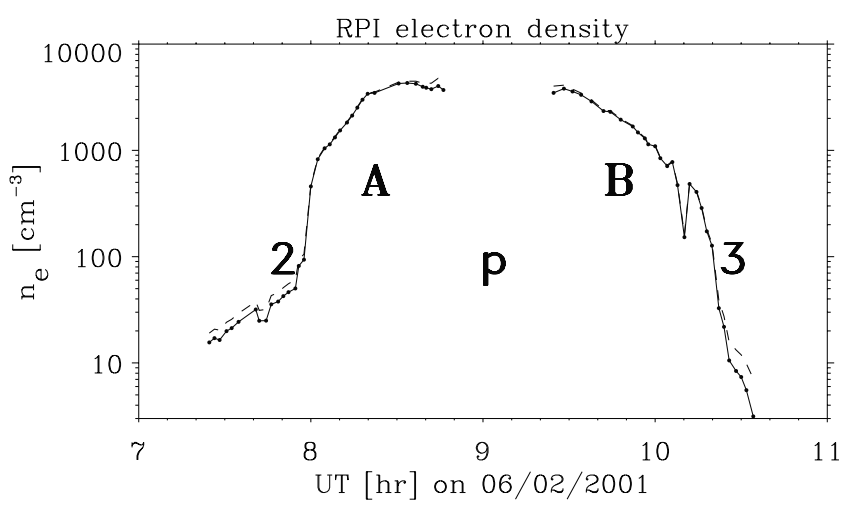

Figure 3b. The $f_{\text {uh }}$ or $f_{\text {pe }}$ line from the RPI spectrogram of Figure $3 \mathrm{a}$ has been extracted and converted to electron number density $n_{\mathrm{e}}$. Plasmaspheric lobes $\mathrm{A}$ and $\mathrm{B}$ are labeled, and points 2, p, and 3 from the orbit plot of Figure 1 are indicated.

lobes encountered by IMAGE during this portion of its orbit. Variations in the frequency of the noise band should not to be confused with occasional data dropouts, which appear as tall, rectangular regions of dark gray extending down to $100 \mathrm{kHz}$. (For example, two intervals of data dropout are labeled "DD" in the spectrogram.)

[13] Figure $3 b$ shows the electron density (along the spacecraft trajectory) extracted from the noise band in the dynamic spectrogram, by taking either the upper edge as $f_{\text {uh }}$ or a partial cutoff at the noise band's lower edge as $f_{\text {pe }}$. The extracted $n_{\mathrm{e}}$ profile is plotted as a solid line. Referring back to Figure 1, the spectrogram time range (0700-1100 UT) covers the portion of the orbit starting just before point 2 and ending just beyond point 3 . The steep gradients at 2 and 3 are the dawn and dusk plasmapause, respectively. In Figures $3 \mathrm{a}$ and $3 \mathrm{~b}$ the dawn and dusk plasmasphere lobes are labeled "A" and "B," respectively. Points 2, 3, and $p$ (from the orbit plot) are labeled in the extracted profile of Figure 3b.

[14] There is a degree of subjectivity in the identification of the UHR noise band and the extraction of $f_{\text {uh }}$ or $f_{\text {pe. It can }}$ be difficult to reliably determine the $f_{\text {pe }}$ cutoff (especially for lower densities outside the plasmasphere) owing to the presence of finite wave intensity below $f_{\text {pe }}$ and above the L- or Z-mode cutoff [Mosier et al., 1973]. The $f_{\text {uh }}$ cutoff is usually more pronounced, but using $f_{\text {uh }}$ to calculate electron density incorporates the inherent uncertainty of the model $f_{\text {ce. }}$. The method used for this study was to locate $f_{\text {uh }}$ and to calculate $f_{\mathrm{pe}}$ (and thus $n_{\mathrm{e}}$ ) using the model $f_{\text {ce }}$. The density value was then verified by the presence of a cutoff (of some kind) at the calculated $f_{\text {pe }}$.

[15] A measure of the uncertainty due solely to subjectivity can be found in the difference between $f_{\mathrm{uh}}$ and $f_{\mathrm{pe}}$. In Figure $3 \mathrm{~b}$ the electron density is the solid line, calculated from the inferred $f_{\mathrm{pe}}$. The dashed line is an alternate quantity $n_{\mathrm{e}}^{\text {uh }} \equiv f_{\mathrm{uh}}^{2} /(8.98 \mathrm{kHz})^{2}$, that is essentially the electron density calculated assuming no difference between $f_{\text {uh }}$ and $f_{\text {pe }}$. Because the subjective error in determining $f_{\text {uh }}$ or $f_{\mathrm{pe}}$ is usually less than the thickness of the noise band, the spacing between the solid line $\left(n_{\mathrm{e}}\right)$ and the dashed line $\left(n_{\mathrm{e}}^{\mathrm{uh}}\right)$ is an upper limit on the uncertainty of $n_{\mathrm{e}}$. As shown in Figure $3 \mathrm{~b}$, there is no visual difference between $n_{\mathrm{e}}$ and $n_{\mathrm{e}}^{\text {uh }}$ for most of the interval (quantitatively, the difference is between 2 and 10 percent). It is only outside the plasmapause (to the left of point 2 or to the right of point 3 ) or close to perigee $\mathrm{p}$ (where $f_{\text {ce }}$ is comparable to $f_{\mathrm{pe}}$ ) that this difference is appreciable (20-30 percent) and visible. Assuming 20 percent uncertainty in the model $f_{\text {ce }}$ (which is an overestimate for most of June 2001, which was not a very disturbed month), the magnetic field model contributes an additional error that is at most about half of the subjective error. This indicates that the total uncertainty in $n_{\mathrm{e}}$ (due to both subjectivity and to the model $f_{\text {ce }}$ ) is small inside the plasmasphere but can in principle be an order of magnitude larger outside the plasmasphere. However, this is an upper limit on the uncertainty; in general, agreement of $f_{\mathrm{uh}}$ and $f_{\mathrm{pe}}$ with observed features of the spectrogram, increases confidence in $n_{\mathrm{e}}$. In principle, RPI resonance sounding [Reinisch et al., 2001] can be used to obtain $f_{\text {ce }}$ to about $0.1 \%$ and $f_{\text {pe }}$ to about $1 \%$. However, for routine extraction of electron density, it is more practical to use the passive wave measurements alone. Finally, there is an additional complication: although we shall assume that electron density is constant along magnetic field lines, this is not strictly true. Goldstein et al. [2001] and Denton et al. [2002] showed that along a given field line $n_{\mathrm{e}}$ increases with latitude; this variation along field lines is very weak inside the plasmasphere but is larger in the plasmatrough region. For our data set (June 2001), IMAGE sampled the plasmasphere at magnetic latitudes $|\lambda| \leq 20^{\circ}$, and the plasmatrough at $20^{\circ}$ $\leq|\lambda| \leq 40^{\circ}$. Applying the results of Denton et al. [2002] to our data set, the assumption of constant $n_{\mathrm{e}}$ along field lines (i.e., assuming that medium-latitude $n_{\mathrm{e}}$ measurements are equatorial values) implies overestimating electron density by no more than 10 percent in the plasmasphere and about 30 percent in the plasmatrough. For profiles with a gradually decreasing density and no clear plasmapause (see section 5) the overestimate is between 10 and 20 percent. In any case, as will be explained in the next section, the uncertainty of the measured $n_{\mathrm{e}}$ does not influence the main result of this study.

\section{Methodology}

[16] In order to compare the EUV $\mathrm{He}^{+}$edges to the RPI electron density gradients, the following methodology was used for each orbit of June 2001:

[17] 1. For each dawnside plasmapause crossing, a "steep gradient" was visually identified in the RPI dynamic spectrogram. A line segment of $n_{\mathrm{e}}$ versus $L$ was recorded for each gradient.

[18] 2. Two EUV images were selected: one before and one after the RPI-observed plasmapause crossing. The time difference between the RPI measurement and each of the EUV images was minimized.

[19] 3. From each image the $\mathrm{He}^{+}$edge was extracted at approximately the same magnetic longitude as the RPI gradient. To account for the time difference between the measurements, the RPI gradient was rotated to its corresponding local time in each of the two EUV images, assuming strict corotation of the plasmasphere. This rotated local time was assumed to be the magnetic longitude of the RPI gradient. The maximum time difference between the 


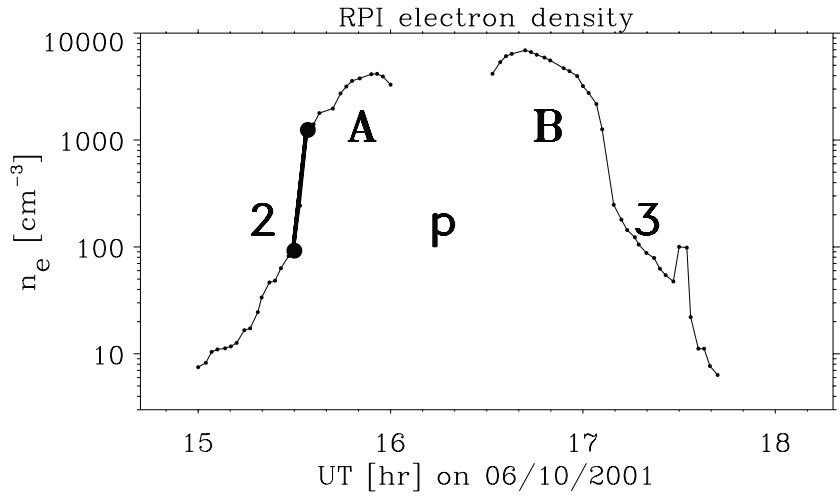

Figure 4. Electron density $n_{\mathrm{e}}$ extracted from RPI spectrogram, 1500-1800 UT on 10 June 2001. RPI observed a steep gradient ("2") at the dawnside plasmapause at 1530 UT.

RPI and EUV measurements was 10.8 hours, and the average time difference was 4.6 hours.

[20] 4. The $L$ values of the RPI gradients and the EUV $\mathrm{He}^{+}$edges were compared. When possible, the EUV $L$-shell was calculated as an average of two EUV images that bracketed the RPI measurement in time. This was done to minimize the effects of erosion or refilling in the intervening time.

[21] The procedure (1)-(4) was attempted for dawnside plasmapause crossings in each of the 51 orbits of the IMAGE satellite during June 2001. Duskside plasmapause crossings were not included in this study. Two of the 51 orbits had RPI line segments for which both of the endpoints were below $50 \mathrm{~cm}^{-3}$ and were excluded on the grounds that such low densities were near or below the lower sensitivity threshold of EUV (see section 5). Two of the orbits had no available/interpretable EUV images. Out of the remaining 47 orbits, 15 orbits had only one EUV image (either before or after the RPI measurement) that permitted reliable extraction of the $\mathrm{He}^{+}$edge. Thus 47 orbits were analyzed using our methodology: 32 used two EUV measurements per RPI dynamic spectrogram, and 15 used only one EUV measurement per RPI dynamic spectrogram.

[22] 10 June 2001 will be used as an example to illustrate the details of the methodology outlined above. Figure 4 shows the extracted RPI electron density $\left(n_{\mathrm{e}}\right)$ profile from 10 June. On this day, IMAGE crossed the dawnside plasmapause at 1530 UT (labeled " 2 "). The steep gradient in electron density there can be represented by a single line segment, overplotted in Figure 4 as a bold line. The two endpoints of this line segment (plotted as filled circles) both occur at 7.4 hours MLT. The outer (inner) endpoint has an $L$ value of 2.9 (2.6).

[23] EUV remote sensing occurs from outside the plasmasphere, near apogee. On 10 June, EUV images were produced during intervals 0421-1335 UT and 1921-2357 UT. The two EUV images closest in time to the 1530 plasmapause crossing are therefore 1335 ( $\sim 2$ hours before) and 1921 UT ( $\sim 4$ hours after). Continuing the point-labeling scheme of Figure 1, these are points 1 and 4, respectively.

[24] Plotted in Figures 5a and 5b are extracted $\mathrm{He}^{+}$edges from 1335 and $1921 \mathrm{UT}$, mapped to the magnetic equator. Both $\mathrm{He}^{+}$edge plots have the same format: the view is from

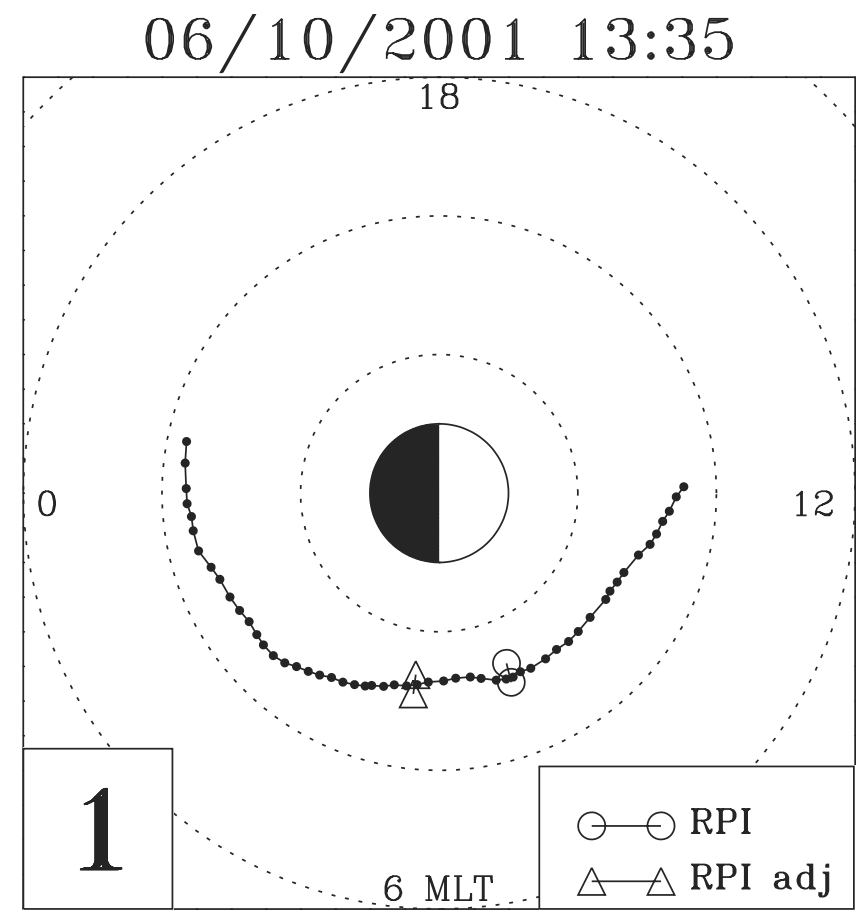

Figure 5a. Extracted EUV He ${ }^{+}$edge from 1335 UT on 10 June, preceding the RPI dawnside plasmapause measurement of Figure 4 by about 2 hours. The RPI plasmapause at point " 2 " has been adjusted in MLT to account for the time delay between RPI and EUV measurements.

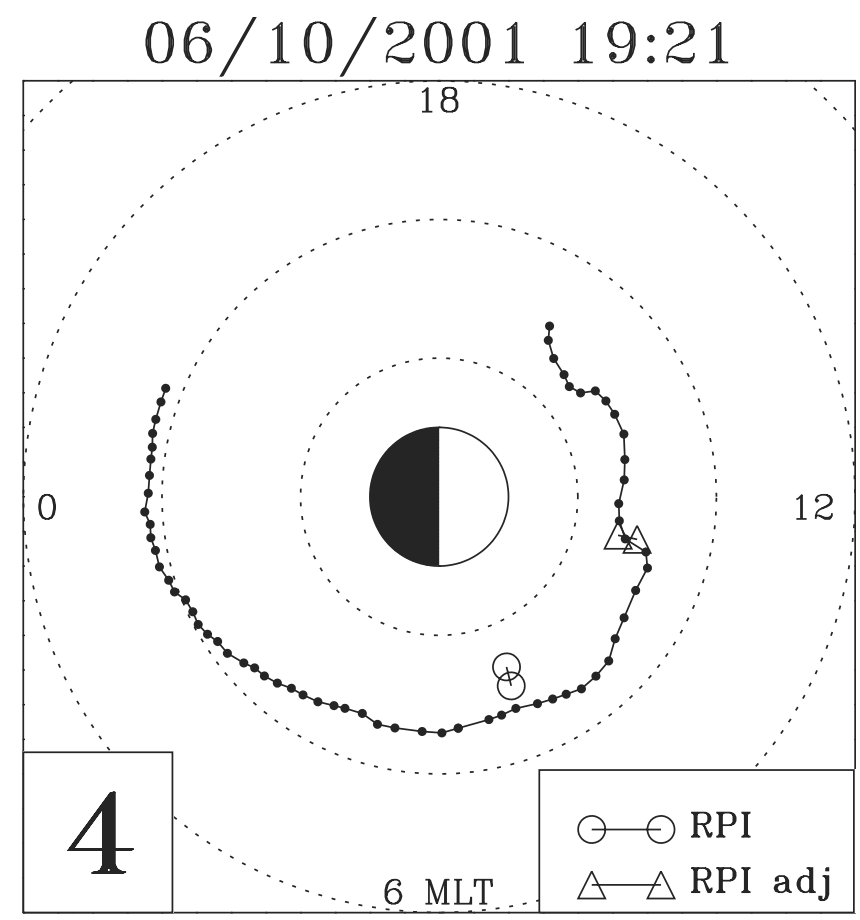

Figure 5b. Extracted EUV $\mathrm{He}^{+}$edge from $1921 \mathrm{UT}$ on 10 June, trailing the RPI dawnside plasmapause measurement of Figure 4 by about 4 hours. 


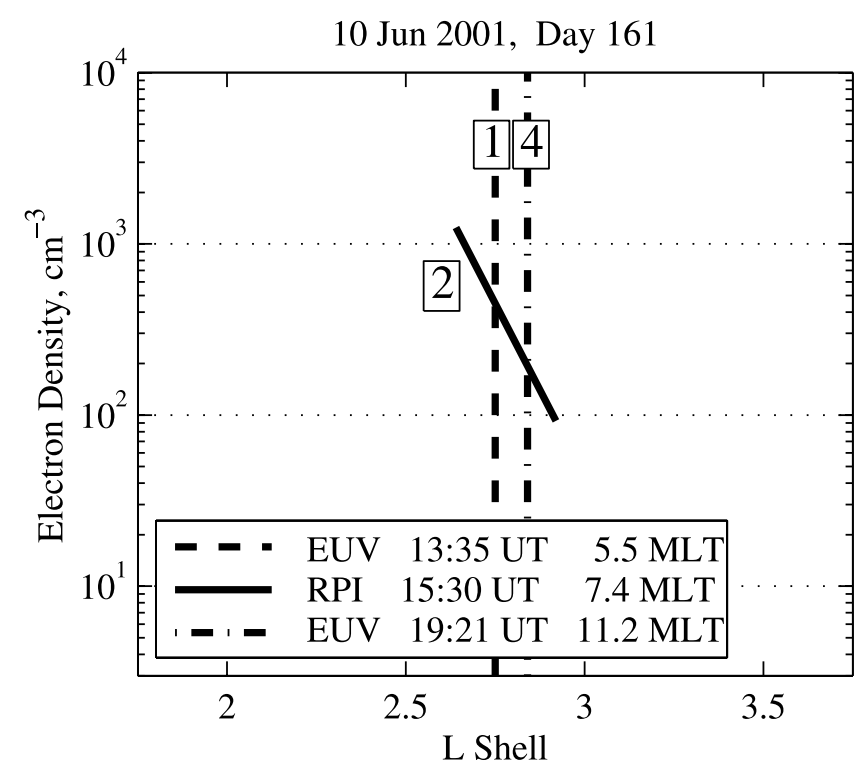

Figure 6. The 1530 UT RPI plasmapause ("2") from Figure 4 is plotted, along with the two bracketing EUV measurements from 1335 ("1") and 1921 ("4").

above the north pole, noon is to the right, and the extracted EUV $\mathrm{He}^{+}$edge is the chain of small filled circles. In the lower left of each plot is the number label of each measurement (either " 1 " or " 4 "). In order to meaningfully compare the $\mathrm{He}^{+}$edge to the RPI plasmapause line segment of Figure 4, some assumption was needed to account for the time difference between RPI and EUV measurements. We assumed strict corotation of the plasmasphere with the Earth. Thus to map to the $\mathrm{He}^{+}$edge at 1335 UT in Figure 5a, the RPI line segment (at 1530 UT and 7.4 MLT) was rotated back by 1.9 hours of local time, from 7.4 MLT to 5.5 MLT. The rotated RPI line segment is plotted as hollow triangles (labeled "RPI adj"). For reference, the unrotated RPI line segment is also plotted (as open circles, labeled "RPI"). Similarly, in Figure 5b (1921 UT), the RPI plasmapause was rotated forward 3.8 hours from 7.4 MLT to 11.2 MLT. Note that the endpoints of the RPI line segment (in either Figure $5 \mathrm{a}$ or Figure $5 \mathrm{~b}$ ), are within $0.3 L$ of each other, indicating a very steep plasmapause gradient.

[25] In each of Figures $5 \mathrm{a}$ and $5 \mathrm{~b}$ the $L$ value of the $\mathrm{He}^{+}$ edge at the magnetic longitude of the RPI line segment (of Figure 4) can be found where the rotated RPI line segment ("RPI adj") crosses the EUV $\mathrm{He}^{+}$\} edge. To check agreement between the RPI and EUV measurements, Figure 6 shows the RPI line segment (density versus $L$ ), with the $L$-values of the two EUV measurements overlayed as vertical lines. The legend at the bottom of the plot gives the UT and MLT values of each of the measurements and they are labeled in the plot according to the established numbering scheme. From Figure 6 and the preceding Figures $5 \mathrm{a}$ and $5 \mathrm{~b}$ it can be seen that the $\mathrm{He}^{+}$edge from either of the EUV measurements agrees quite well with the location of the RPI plasmapause, mapped in MLT according to strict corotation. Taken alone, this suggests that the $\mathrm{He}^{+}$ edge is indeed the visual signature of a steep density gradient at the plasmapause. The goal of this study was to perform such a comparison for a sufficient number of cases to determine the reliability of this association between the EUV $\mathrm{He}^{+}$edge and the plasmapause. In such a study, where the $L$ location of the plasmapause is of primary interest, the uncertainty in the RPI density extraction (discussed in section 2) is not a major source of error.

[26] It can be seen from Figure 5b that any azimuthal structure (such as ripples, bumps, tails, etc.) on the plasmapause can have a significant impact on the result of the comparison, especially if the assumption of strict corotation is even slightly violated. This is why duskside plasmapause comparisons were not included in this study. Azimuthal/ radial structure of the plasmapause is prevalent in the dusk sector, especially due to the presence of convection tails during active times. Strict corotation may be a poor assumption in the dusk sector, where evidence indicates a flow stagnation point resides [see, e.g., Carpenter and Anderson, 1992; Laakso and Jarva, 2001; Moldwin et al., $2002 \mathrm{~b}$, and references therein]. Therefore a rule of thumb for dealing with time gaps between RPI and EUV measurements is not so reliably made for the dusk sector. In addition, shallow density gradients (with no clear plasmapause) are more prevalent near dusk.

[27] Our study assumes that the plasmapause is roughly field-aligned [e.g., Foster et al., 2002]. A small violation of this assumption would produce a slight disagreement in $L$ between the equatorial plasmapause location seen by EUV and the in situ RPI plasmapause location, typically measured at a latitude of at 20 to 40 degrees. Laakso and Jarva [2001] deduced plasmapause locations from single-point spacecraft potential measurements by the Polar satellite. Their observations might imply that there is a slight difference between the plasmapause $L$-values observed at two spots with the same local time but separated in latitude. However, any two plasmapause measurements along Polar's orbit are also separated in time (generally by at least an hour), during which the plasmasphere is presumably rotating. Any azimuthal irregularities might exaggerate the latitudinal variation of the plasmapause location.

[28] Temporal variations in the plasmapause location can also affect this type of study. The plasmapause moves in response to changes in the strength of magnetospheric convection. Generally speaking, this motion is predominantly radial. That is, the plasmapause erodes (moves rapidly inward on a time scale as fast as a few hours) if convection increases, and it refills or recovers (moves slowly back outward over the course of a day or a few days) when convection tapers off. If convection strength fluctuates rapidly, then the simple picture of radial motion (inward or outward) is inadequate, as there will be azimuthal structure created by inhomogeneities in the global convection field and by finite penetration of this convection field to inside the plasmasphere. The index $K_{\mathrm{p}}$ is a global 3-hour measure of magnetic activity based on perturbations from quiet-day conditions, measured at midlatitude stations. For this study it is ideal to have a moderate $K_{\mathrm{p}}(2-3)$ during the time gaps between RPI and EUV measurements. Values of $K_{\mathrm{p}}$ outside this moderate range will tend to decorrelate the time-separated EUV and RPI measurements. High $K_{\mathrm{p}}$ indicates geomagnetic activity (i.e., enhanced magnetospheric convection) that precipitates erosion of the plasmapause. Sustained low $K_{\mathrm{p}}$ conditions may allow refilling, leading to a slow outward progression of the plasmapause, often accom- 
10 Jun 2001, Day 161

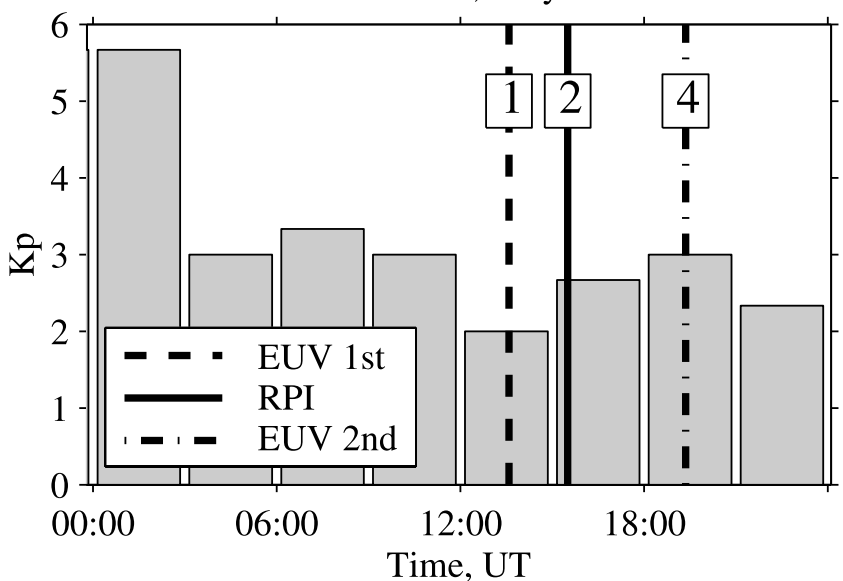

Figure 7. Plot of $K_{\mathrm{p}}$ for 10 June 2001, showing times of the RPI measurement (" 2 ") and the two bracketing EUV measurements ("1") and ("4").

panied by a loss of steepness in the plasmapause profile. Another observed low- $K_{\mathrm{p}}$ effect, perhaps related to spatially nonuniform refilling rates, is an increase in the amount of mesoscale density structure at the plasmapause [Moldwin et al., 1994]. In considering geomagnetic activity during the time gaps between RPI and EUV measurements, both the maximum $K_{\mathrm{p}}$ value and the time history of $K_{\mathrm{p}}$ are important indicators. Figure 7 shows the $K_{\mathrm{p}}$ profile on 10 June. The times of the RPI and EUV measurements are indicated by vertical lines, labeled according to the established numbering scheme. It is seen that on 10 June, $K_{\mathrm{p}}$ was indeed moderate during the time gaps between RPI and EUV measurements, and before the first EUV measurement as well.

[29] In contrast to this good agreement, an erosion event is depicted in Figures 8 and 9. An inward progression of the

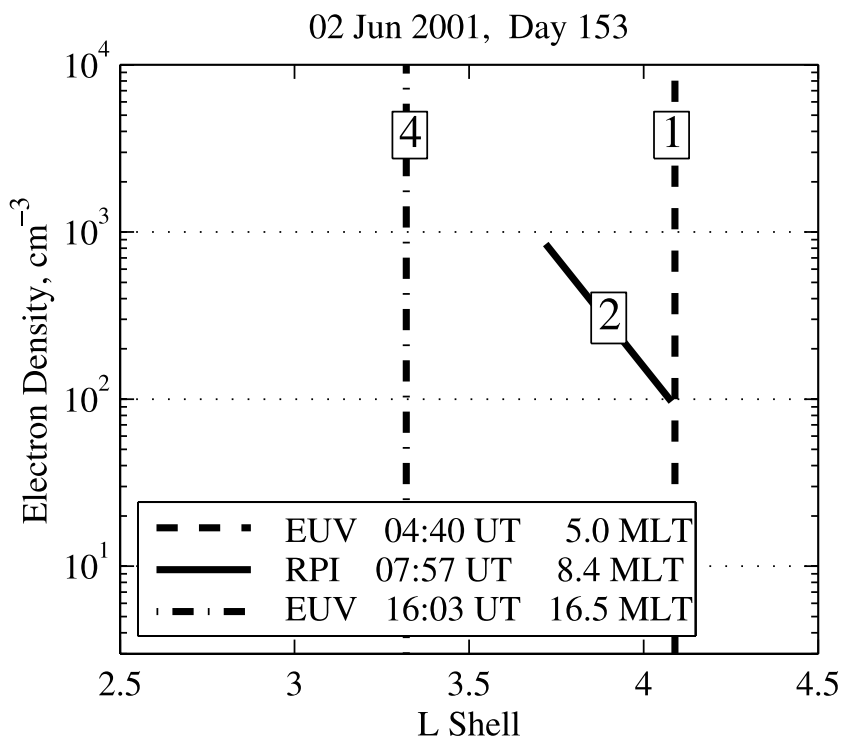

Figure 8. RPI and EUV measurements of 2 June 2001, showing the inward progression (erosion) of the plasmapause between 0440-1603 UT.

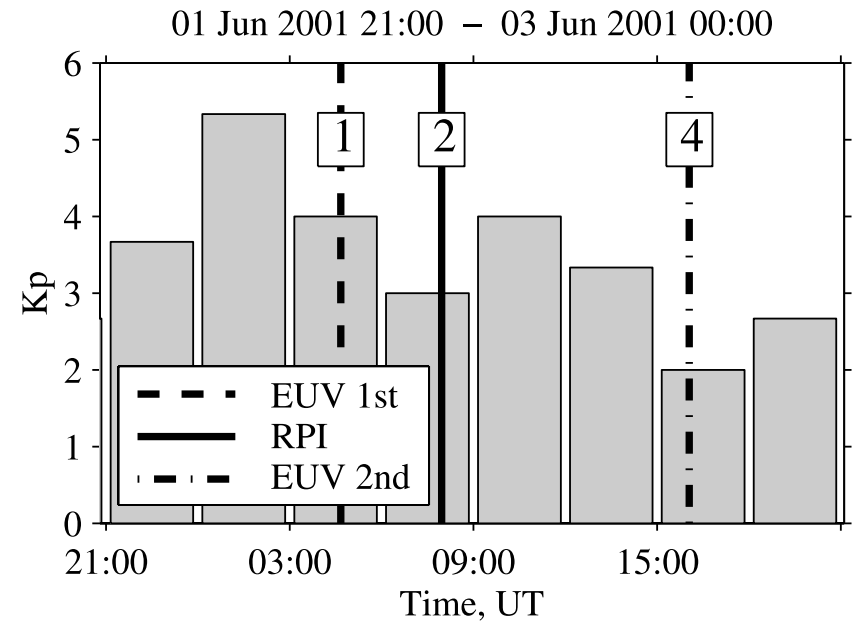

Figure 9. $K_{\mathrm{p}}$ for 2 June 2001, during the observed erosion event of Figure 8.

plasmapause can be seen in three successive measurements on 2 June. At 0440 UT (labeled "1"), EUV observed the plasmapause at $L=4.1$. At 0757 UT ("2"), RPI saw the plasmapause between $L=3.7$ and $L=4.1$. At 1603 UT ("4"), EUV saw it at $L=3.3$. Judging from the $K_{\mathrm{p}}$-profile of Figure 9 and the plasmapause locations at 1,2, and 4 in Figure 8, strong erosion commenced at the beginning of the day and continued at a reduced rate until just before the EUV measurement at 1603 UT ("4"). The EUV image of 1603 UT (used as an example in section 1, Figure 2a) does in fact show a duskside drainage tail, as might be expected if erosion had just occurred (or was still occurring).

[30] As a final example of the comparisons done in this study, a plasmapause recovery event is shown in Figures 10 and 11 . In this case, successive measurements 1,2 , and 4 on 25 June (Figure 10) show the plasmapause moving outward, from $L=4.1$ at 0748 UT to $L=5.2$ at 1618 UT. Figure 11

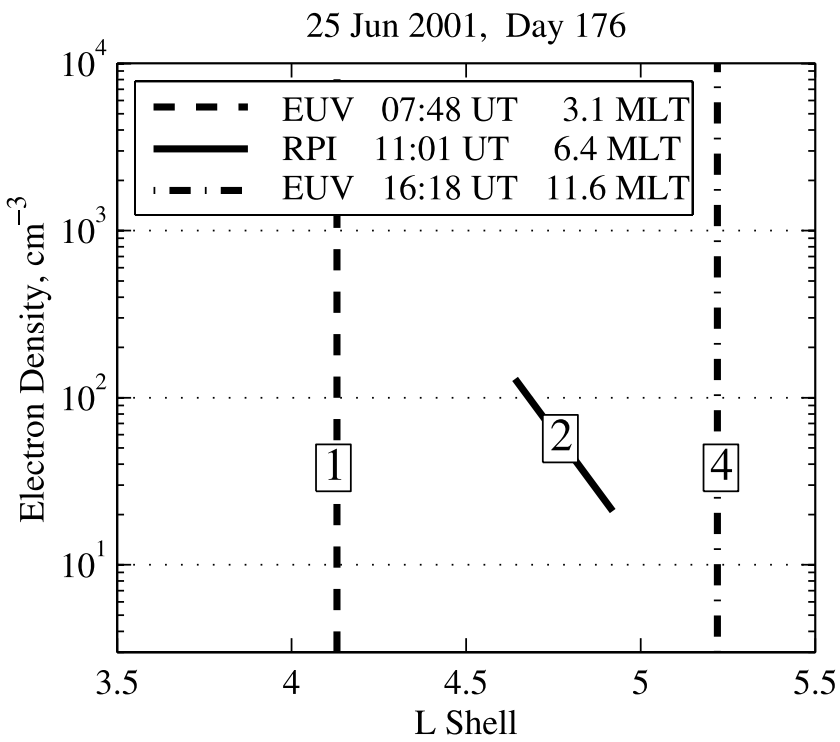

Figure 10. Outward progression (recovery due to refilling) of the plasmapause (as observed by RPI and EUV) between $0748-1618$ UT on 25 June 2001. 
24 Jun 2001 21:00 - 26 Jun 2001 00:00

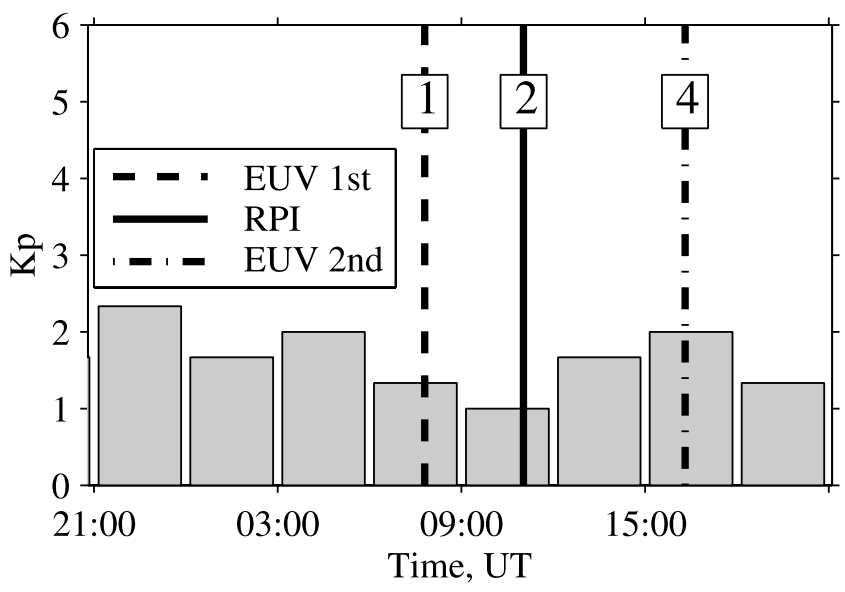

Figure 11. $K_{\mathrm{p}}$ for 25 June 2001, during the observed plasmapause recovery event of Figure 10.

shows that $K_{\mathrm{p}}$ was low $(1-2)$ in the interval covered by 1,2 , and 4; from the low $K_{\mathrm{p}}$ values it can be assumed that convection was quite weak, allowing for ionospheric refilling of depleted outer plasmaspheric flux tubes.

[31] The preceding two cases of temporal variation of the plasmapause location are far from atypical. Out of the 47 orbits analyzed, approximately half showed plasmapause displacements of $0.5 \mathrm{~L}$ or more occurring in the time gap between two EUV measurements or (in the 15 cases in which only one EUV image was available) between the RPI measurement and its corresponding EUV measurement. Despite this tendency toward temporal decorrelation, 34 intervals showed good agreement (within $0.1 L$ ) between the RPI line segment and at least one EUV He${ }^{+}$edge (either the earlier one or the later one); 10 intervals had such agreement among the RPI line segment and both EUV He ${ }^{+}$edges.

\section{Results}

[32] At the end of the previous section, the decorrelation between temporally separated measurements was discussed. One way to minimize the effects of the temporal decorrelation is to use the EUV image that occurred closest in time to the RPI plasmapause crossing. Except in a few examples where EUV data gaps occurred, the closest EUV measurement was taken a few hours before the RPI-observed dawnside plasmapause crossing. Taking this first approach, we define $L_{\mathrm{RPI}}$ as the $L$ value at the midpoint of each RPI gradient line segment, and we define $L_{\mathrm{EUV}}$,closest as the $L$ value of the $\mathrm{He}^{+}$edge from the EUV image closest in time to the RPI measurement. A plot of $L_{\mathrm{EUV}}$,closest versus $L_{\mathrm{RPI}}$ is shown in Figure 12a. The length of the horizontal bar on each data point is $\left(d \log n_{\mathrm{e}} / \mathrm{dL}\right)^{-1}$; i.e., is inversely proportional to the steepness of the RPI gradient. A quantitative plot of the steepness of the RPI gradients is found in Figure $12 \mathrm{~b}$, a plot of $\mathrm{d} \log \mathrm{n}_{\mathrm{e}} / \mathrm{dL}$ versus $L$ for all of the RPI plasmapause line segments, where each $L$-value is taken as the midpoint of the corresponding line segment. The general trend in Figure 12b is that steeper gradients are found at lower $L$, in agreement with the model of Gallagher et al. [1988], indicated by the solid curve. Very shallow gradients (large horizontal bars in Figure 12a or low values of d log

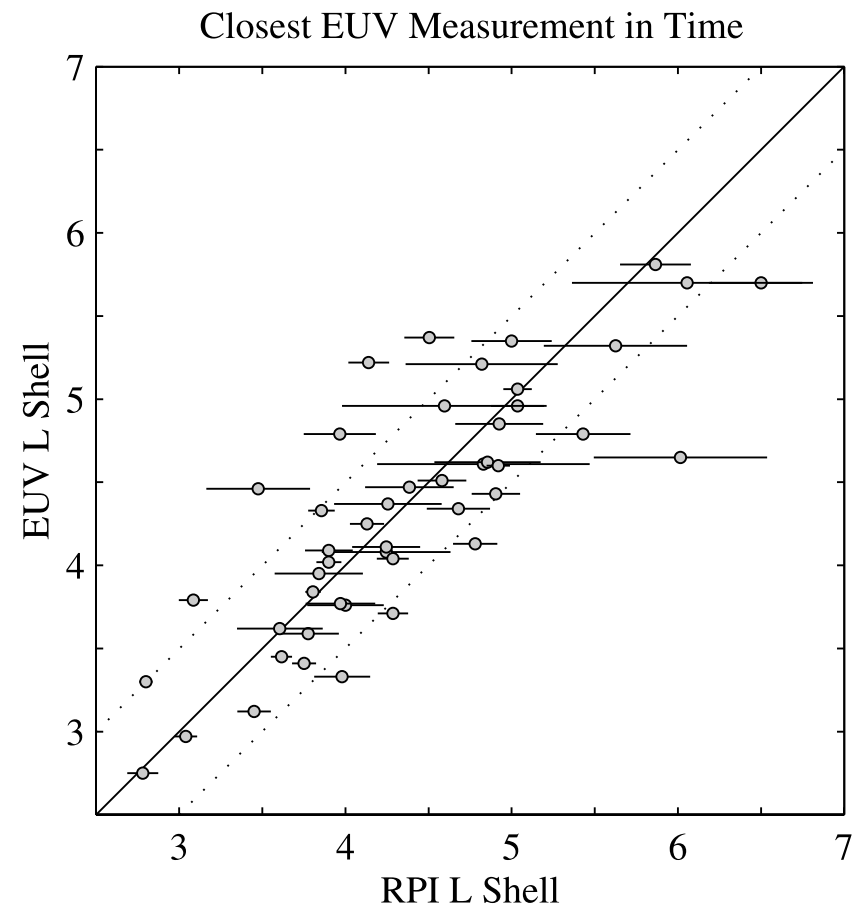

Figure 12a. Plot of the $L$ locations of the plasmapause, as seen by EUV, versus those seen by RPI. The EUV measurement used is the one closest in time to the RPI measurement. The correlation is 0.83 .

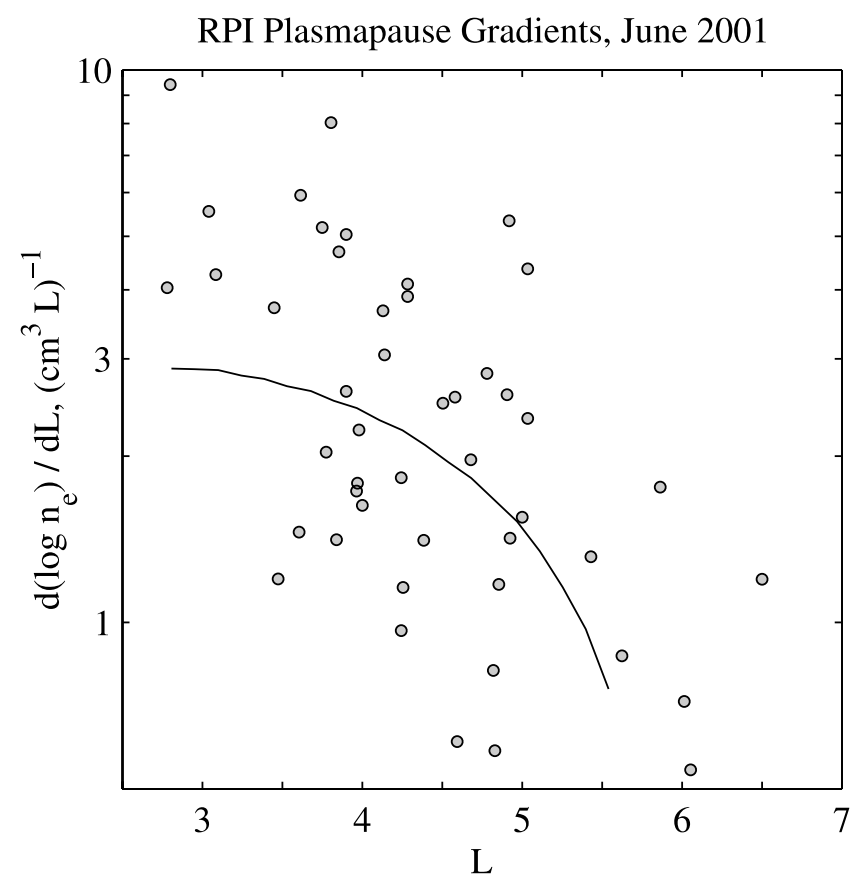

Figure 12b. Steepness of the plasmapause gradient (d log $\mathrm{n}_{\mathrm{e}} / \mathrm{d} L$ ) versus the midpoint $L$ for all of the RPI measurements. The gradients are steeper for lower $L$. The solid curve is the same quantity, derived from the model of Gallagher et al. [1988]. 


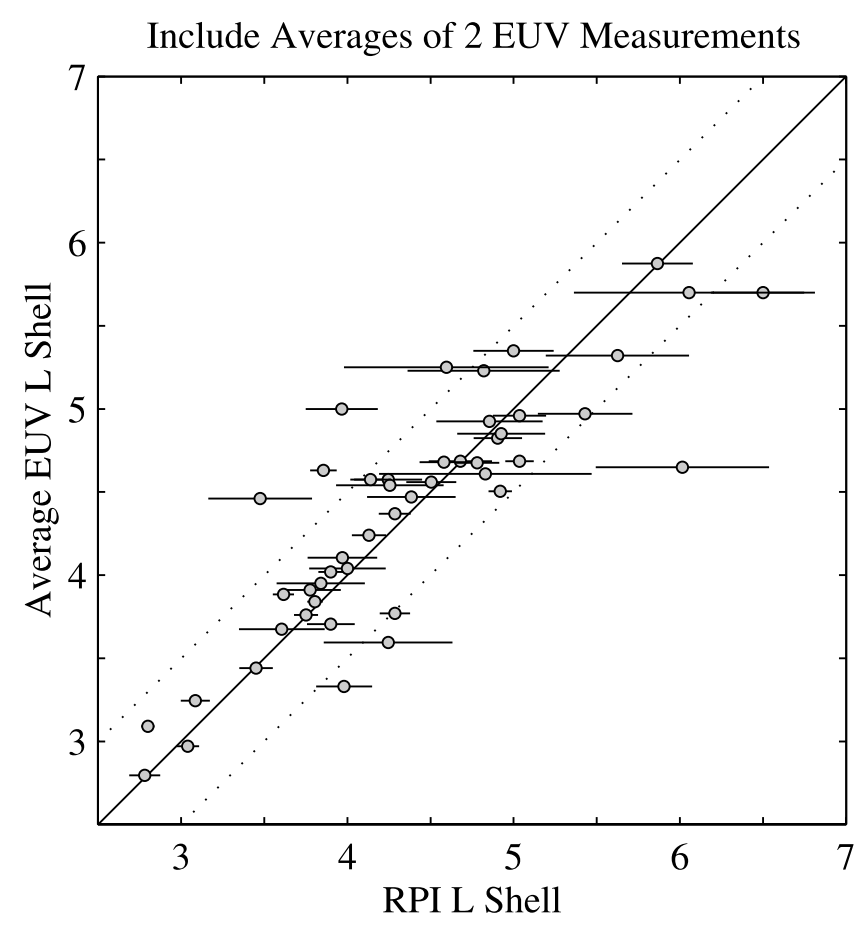

Figure 13. Same as Figure 12a, except the EUV $L$-shell is an average of two EUV measurements, where available. The correlation is 0.86 .

$\mathrm{n}_{\mathrm{e}} / \mathrm{dL}$ in Figure 12b) are due to the fact that "steep gradients" were selected from RPI dynamic spectrograms (plots of log frequency versus UT), as opposed to plots of $\log$ density versus $L$. There were several cases where gradients seemed steep in RPI dynamic spectrograms, but this apparent steepness was due to rapid motion of IMAGE past a shallow gradient, or to the horizontal plot scale used. As will be shown in section 5, the shallow gradient can be used to estimate the lower sensitivity threshold of the EUV cameras.

[33] There are 47 points plotted in Figure 12a. If $L_{\mathrm{EUV}}$,closest and $L_{\mathrm{RPI}}$ agreed perfectly, all the points would lie along the solid diagonal center line $L_{\mathrm{EUV}, \text { closest }}=L_{\mathrm{RPI}}$. In fact, 77 percent of the points are within $0.5 \mathrm{~L}$ of perfect agreement. (For reference, dotted lines are drawn at $L_{\mathrm{EUV}, \text { closest }}=L_{\mathrm{RPI}} \pm$ 0.5.) There is less scatter in the steeper gradients (small horizontal bars). The correlation between $L_{\mathrm{EUV}, \text { closest }}$ and $L_{\mathrm{RPI}}$ is 0.83 (highly significant).

[34] A second way to minimize the temporal decorrelation between the measurements is to take advantage of the fact that 32 orbits had two available EUV plasmapause measurements. Suppose erosion or recovery occurred during the time spanned by measurements 1 (EUV), 2 (RPI), and 4 (EUV). Then (as shown in Figure 8 or Figure 10) the RPI plasmapause $L$ would lie somewhere between the two EUV plasmapauses. Therefore averaging the two EUV measurements should (at least partially) compensate for the effect of erosion or recovery. We define $L_{\mathrm{EUV} \text {,avg }}$ as the average of the two EUV measurements, if two are available. In cases where only one EUV plasmapause was measurable, $L_{\mathrm{EUV}, \text { avg }} \equiv L_{\mathrm{EUV}, \text { closest }}$.

[35] A plot of $L_{\mathrm{EUV}, \text { avg }}$ vs $L_{\mathrm{RPI}}(47$ points) is shown in Figure 13. In this plot, 55 percent of the points are within
$0.25 \mathrm{~L}$ of perfect agreement, and 81 percent are within $0.5 \mathrm{~L}$. That is, in comparison with the previous plot (Figure 12a), many of the points are much closer to the center line, especially between $3<L<5$. The tendency of steeper gradients to be less scattered from the center line is also more pronounced for this plot. The correlation between $L_{\mathrm{EUV}, \text { avg }}$ and $L_{\mathrm{RPI}}$ is 0.86 (highly significant). This high degree of correlation between $L_{\mathrm{EUV} \text {,avg }}$ and $L_{\mathrm{RPI}}$ might be surprising, especially considering that the averaging of the two EUV plasmapause positions implicitly assumes that the displacement rate of the plasmapause is constant for many hours, which is probably not true (particularly if an erosion/ refilling event began or ended during the time-gap between measurements). There is still a significant amount of scatter in the plot, particularly for RPI edges with shallow gradients. This scatter can be attributed to other sources of error in the method, including (a) intrinsic uncertainty in the RPI and EUV extractions, (b) deviations from the dipole field assumed in the EUV extraction, especially at large $L$, (c) violations of the strict corotation assumption, (d) azimuthal structure of the plasmapause, (e) latitudinal dependence of the plasmapause location, and (f) weak latitudinal dependence of electron density along field lines (as mentioned in section 2).

[36] For comparison, Figure 14 presents a plot of $L_{\text {EUV,avg }}$ versus $L_{\mathrm{RPI}}$ but only including the 32 points for which there were two EUV measurements available. (This plot excludes points that did not change between Figure 12a and Figure 13.) The correlation in this case is 0.87 .

[37] In section 2 it was mentioned that manual extraction of the $\mathrm{He}^{+}$edge from EUV data involved some subjectivity. It was estimated that this uncertainty was $0.2 R_{\mathrm{E}}$ (for sharp edges) and at least $0.4 R_{\mathrm{E}}$ (for diffuse edges). To get another

\section{Only Averages of Exactly 2 EUV Measurements}

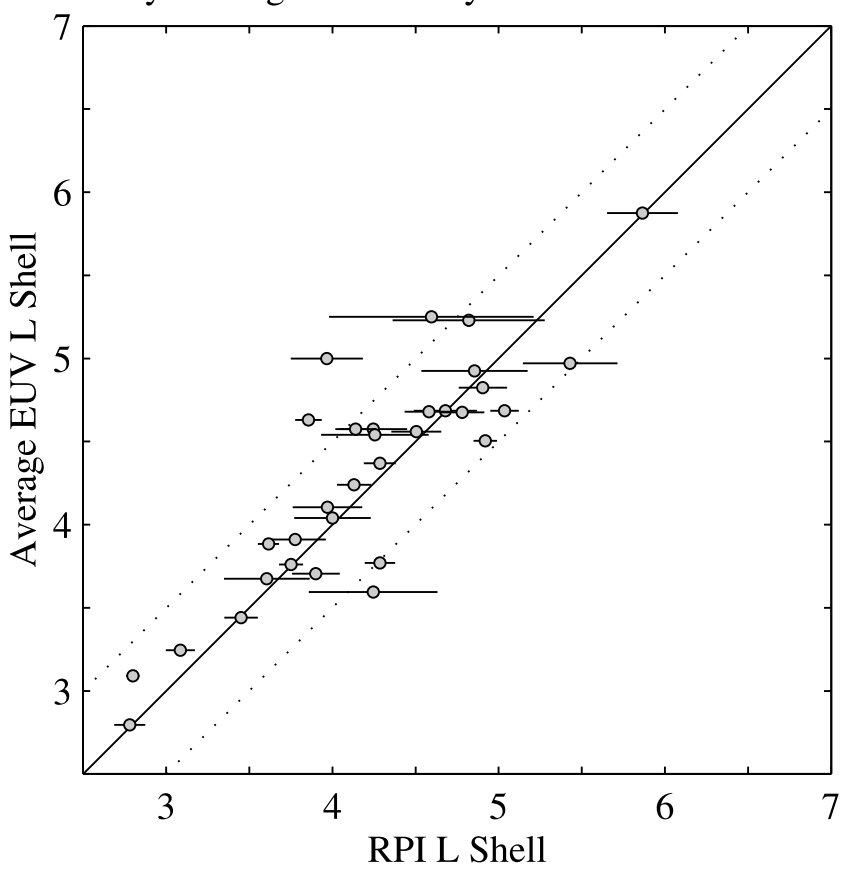

Figure 14. Same as Figure 13, except that 15 points for which only one EUV measurement was available have been removed. The correlation is 0.87 . 


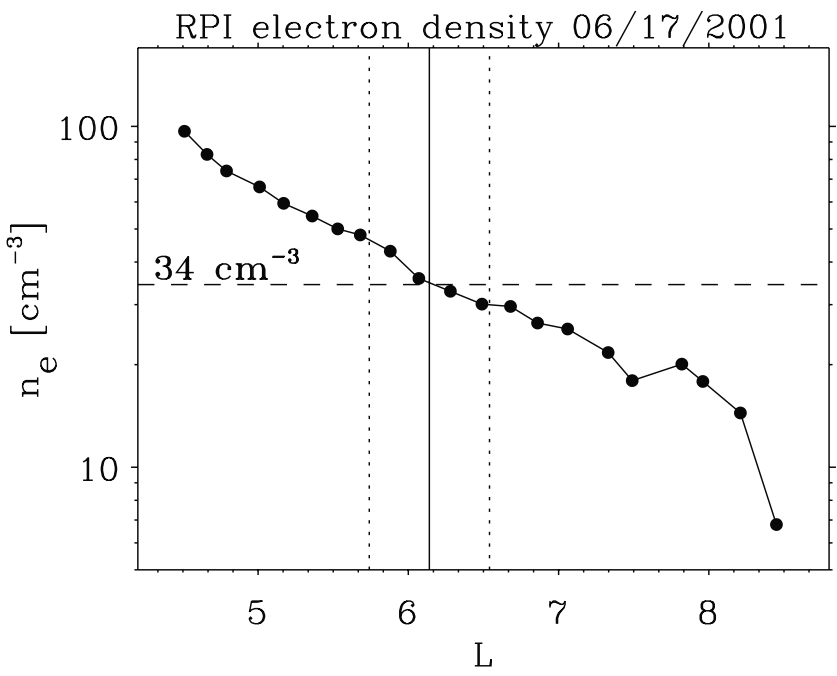

Figure 15. A shallow gradient in electron density $n_{\mathrm{e}}$ as observed by RPI on 17 June 2001, as IMAGE passed through the outer plasmasphere on the dusk side.

estimate, two versions of this study were performed independently by the first two authors of this paper. That is, each author performed the extraction of all EUV edges corresponding to RPI gradients of June 2001. The difference between the two sets of measurements was judged to be the uncertainty due to subjectivity in the EUV edge extraction. The difference between the two measurements was less than $0.25 R_{\mathrm{E}}$ for 73 percent of the images. The images for which there was greater than $0.25 R_{\mathrm{E}}$ difference tended to correspond to a gradual roll-off in the intensity of the image, rather than a sharp, well-defined $\mathrm{He}^{+}$edge.

\section{EUV Lower Threshold}

[38] Shallow density gradients measured by RPI can be used to estimate the lower sensitivity threshold of the EUV cameras. Figure 15 shows the electron density profile measured by RPI as IMAGE passed through the duskside outer plasmasphere on 17 June 2001, between 0600-0700 UT (spanning $L$-values 5-8). EUV produced its first image of the day at $0730 \mathrm{UT}$, but due to the significant plasma densities out to $L=8$, the full extent of the duskside plasmasphere was not captured in EUV's field of view until shortly before 1238 UT, shown in Figure 16. The Sun is to the right, so the duskside plasmasphere observed in situ by RPI is near the top of the frame. Unlike steep gradients, the gradual density drop-off of Figure 15 does not produce a sharp $\mathrm{He}^{+}$ edge in an EUV image. Instead, it shows up as a diffuse edge, as illustrated in Figure 16. The extracted $\mathrm{He}^{+}$edge, mapped to the equator, is shown in Figure 17. The portion of the duskside plasmasphere sampled by RPI is indicated by IMAGE's trajectory, mapped to the equatorial plane.

[39] The lower sensitivity threshold (LST) of the EUV instrument's cameras is defined as the density below which EUV cannot detect $\mathrm{He}^{+}$above the background noise. The background noise is somewhat variable, but generally it looks similar to the dark region surrounding the plasmasphere in Figure 16. Therefore if the diffuse edge in the EUV image corresponds to the gradually dropping RPI

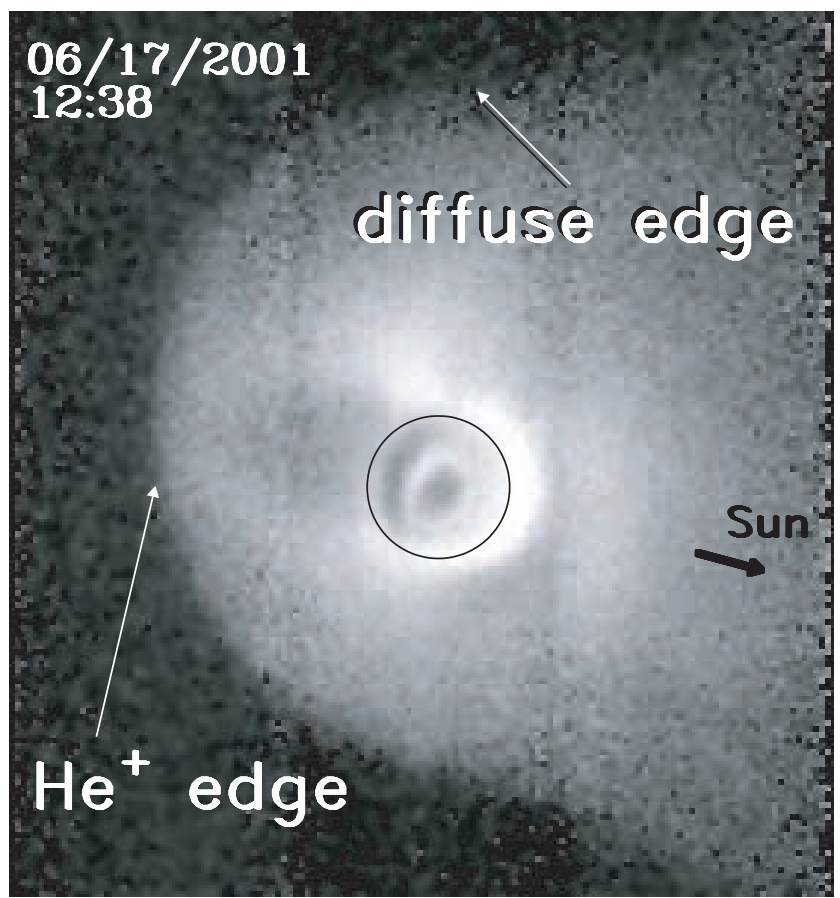

Figure 16. EUV image taken after emerging from the duskside plasmasphere on 17 June 2001. The diffuse edge near dusk corresponds to the shallow density profile of Figure 15.

density of Figure 15, then the spot where the $\mathrm{He}^{+}$emissions fade into the background noise corresponds to the LST. This spot is indicated in Figure 17 by a black dot where the IMAGE trajectory crosses the extracted $\mathrm{He}^{+}$edge. The $L$

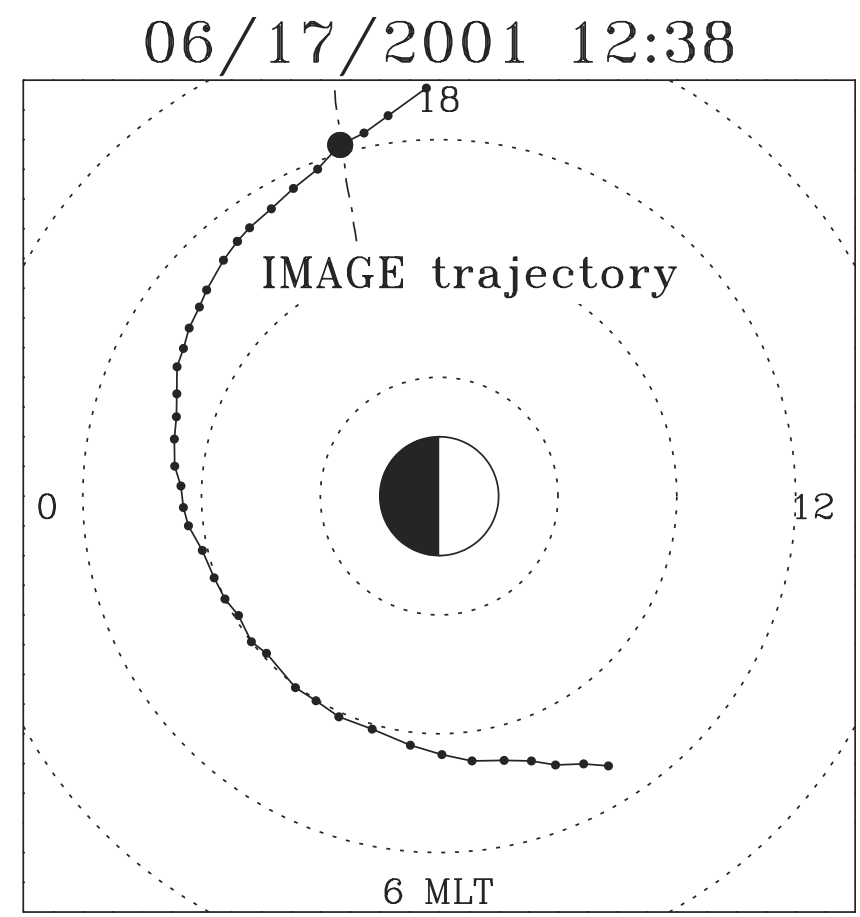

Figure 17. $\mathrm{He}^{+}$edge extracted from the EUV image of Figure 16. The trajectory of IMAGE during the RPI data interval of Figure 15 has been mapped onto the plot as well. 
value of the $\operatorname{dot}(L=6.1)$ is overlayed as a vertical line on the RPI density plot of Figure 15 . Where this vertical line crosses the density profile $\left(34 \mathrm{~cm}^{-3}\right)$ is determined to be the LST. Dotted vertical lines are drawn to indicate $0.4 \mathrm{~L}$ uncertainty in the LST location. The intersection of these dotted lines with the RPI profile gives upper and lower error bars for the LST measurement, due to EUV extraction uncertainty. An additional (but small) contributing source of error in the LST determination is the uncertainty in the RPI density (due to factors discussed in section 2), which we estimate is about 20 percent.

[40] Using intervals in June 2001 for which RPI data had gradual density profiles that could be associated with EUV diffuse edges, 18 LST determinations were performed. The average (weighted according to the errors on each LST point) of these 18 values is $40 \pm 10$ electrons $\mathrm{cm}^{-3}$, where the uncertainty here is the standard deviation of the 18 LST determinations. Assuming that $\mathrm{He}^{+} / \mathrm{H}^{+}$is $0.1-0.2$, this gives a lower threshold of $4-8 \mathrm{He}^{+}$ions $\mathrm{cm}^{-3}$.

[41] Because EUV's returned signal is proportional to the 30.4-nm photon flux, the sensitivity depends on instrument integration time. Each frame of EUV data is an integration of 10 minutes of accumulated 30.4-nm ultraviolet light (as mentioned in section 2). Adding frames in postprocessing can increase the signal-to-noise ratio and hence reduce the LST. The sensitivity of the EUV cameras also varies with solar flux. During June 2001 the solar flux varied between $1.3 \times 10^{10}$ and $1.7 \times 10^{10}$ photons $/\left(\mathrm{cm}^{2} \mathrm{~s}\right)$, based on version 1.17 of the Solar2000 model [Tobiska et al., 2000]. This is a $31 \%$ variation in solar flux, relative to the mean value for this period. Some of the uncertainty in the average LST value $\left(40 \pm 10\right.$ electrons $\left.\mathrm{cm}^{-3}\right)$ can be attributed to variation in the solar flux. The $18 \mathrm{LST}$ values are anticorrelated with the solar flux; when solar flux is high (low), LST values are below (above) the mean LST.

[42] The LST was determined here using density profiles from both the dawn and dusk sectors. As mentioned earlier, the dusk plasmasphere presents a challenge when trying to map RPI data to a temporally separated EUV image. During many instances (especially when the dusk plasmasphere extends out to geosynchronous distance or further), the assumption of strict corotation is probably not even approximately valid for the dusk side. Therefore for the LST determination the following two guidelines were used for the duskside plasmasphere. First, it was assumed that the afternoon plasmasphere corotated between 1200-1600 MLT and 2000-2400 UT and stagnated between 16002000 MLT. Second, to minimize the effects of errors in the co-rotation/stagnation assumption, images in which the EUV plasmapause showed significant azimuthal structure (i.e., large variations with MLT in the $L$ location of the $\mathrm{He}^{+}$ edge) were not included. Uncertainties here suggest that a more rigorous study of the LST should be undertaken in the future. However, an LST value of $30-50$ electrons $\mathrm{cm}^{-3}$ is probably a reasonable first estimate based on in-flight calibration using the Moon and typical profiles of plasma density versus radial position. For the period June 2001 we adopt an average solar 30.4-nm flux of $1.5 \times 10^{10}$ photons/ $\left(\mathrm{cm}^{2} \mathrm{~s}\right)$ based on the Solar2000 model. Using a relationship between the solar flux and g-value computed from Figure 34 of [Meier, 1991], we find an average value of $g=2.2 \times$ $10^{-5} \mathrm{~s}^{-1}$. The background noise level in the image in Figure
16 corresponds to a brightness of $\sim 0.15 \mathrm{R}$ and hence for the value of $\mathrm{g}$ just mentioned a column density integrated along the line of sight of $4.6 \times 10^{9} \mathrm{~cm}^{-2}$. For a typical profile of $\mathrm{He}^{+}$ion concentration versus $L$, and for viewing from high magnetic latitude, this column density corresponds to an equatorial $\mathrm{He}^{+}$concentration of $9 \mathrm{~cm}^{-3}$. If $\mathrm{He}^{+}$constitutes $20 \%$ of the plasma, then the electron density at the equator is $45 \mathrm{~cm}^{-3}$, in good agreement with the value derived earlier by comparing EUV and RPI observations. A study by Moldwin et al. [2002a], comparing geosynchronous in situ density data and EUV images also found an LST of about 30-40 electrons $\mathrm{cm}^{-3}$.

\section{Summary}

[43] We have examined a month of RPI and EUV data and performed a detailed comparison between steep density gradients in RPI data and sharp edges in EUV images. We found an excellent correlation between the RPI steep plasmapause gradient and the sharp $\mathrm{He}^{+}$edge. This implies that the sharp $\mathrm{He}^{+}$edge in EUV images may be reliably interpreted as the plasmapause. Diffuse edges in EUV data are more difficult to interpret; they correspond to a density that gradually decreases with $L$. In many cases a diffuse edge may indicate the lower sensitivity threshold of the EUV cameras, rather than a real boundary. A preliminary comparison of 18 gradual RPI profiles and diffuse EUV edges produced an estimate for this lower threshold of $40 \pm$ 10 electrons $\mathrm{cm}^{-3}$.

[44] Acknowledgments. We are grateful to the World Data Center for Geomagnetism, Kyoto, for the availability of $K_{\mathrm{p}}$ data via the World Wide Web. Discussions with D. Carpenter were very useful. Work at Rice was supported by NASA contract NAS5-96020 subcontracted through Southwest Research Institute, as part of the IMAGE Mission. Work at Stanford was supported by subcontract 03-08482 from the University of Massachussetts at Lowell. Work at the University of Arizona was supported under contract 83818 from SwRI, a subcontract under NASA contract NAS596020. Work at MSFC was supported by the IMAGE Mission from the NASA Office of Space Science. BWR was supported by NASA under subcontract from Southwest Research Institute. SOLAR2000 Research Grade historical irradiances are provided courtesy of W. K. Tobiska and SpaceWx.com. These historical irradiances have been developed with funding from the NASA UARS, TIMED, and SOHO missions. We thank both reviewers of this paper.

[45] Arthur Richmond thanks Mark B. Moldwin and another reviewer for their assistance in evaluating this paper.

\section{References}

Brice, N. M., Bulk motion of the magnetosphere, J. Geophys. Res., 72, 5193, 1967.

Burch, J. L., IMAGE mission overview, Space Sci. Rev., 91, 1, 2000.

Burch, J. L., D. G. Mitchell, B. R. Sandel, P. C. Brandt, and M. Wüest, Global dynamics of the plasmasphere and ring current during magnetic storms, Geophys. Res. Lett., 28, 1159, 2001a.

Burch, J. L., et al., Views of Earth's magnetosphere with the IMAGE satellite, Science, 291, 619, 2001b.

Carpenter, D. L., Whistler evidence of a "knee" in the magnetospheric ionization density profile, J. Geophys. Res., 68, 1675, 1963.

Carpenter, D. L., Earth's plasmasphere awaits rediscovery, EOS Trans. $A G U, 76,89,1995$

Carpenter, D. L., and R. R. Anderson, An ISEE/Whistler model of equatorial electron density in the magnetosphere, J. Geophys. Res., 97, 1097, 1992.

Carpenter, D. L., and J. Lemaire, Erosion and recovery of the plasmasphere in the plasmapause region, Space Sci. Rev., 80, 153, 1997.

Carpenter, D. L., R. R. Anderson, T. F. Bell, and T. R. Miller, A comparison of equatorial electron densities measured by whistlers and by a satellite radio technique, Geophys. Res. Lett., 8, 1107, 1981.

Carpenter, D. L., R. R. Anderson, W. Calvert, and M. B. Moldwin, CRRES observations of density cavities inside the plasmasphere, J. Geophys. Res., 105, 23,323, 2000. 
Chakrabarti, S., F. Paresce, S. Bowyer, S. Chiu, and A. Aikin, Plasmaspheric Helium ion distribution from satellite observations of $\mathrm{He}$ II 304-Ä, Geophys. Res. Lett., 9, 151, 1982.

Comfort, R. H., I. T. Newberry, and C. R. Chappell, Preliminary statistical survey of plasmaspheric ion properties from observations by DE 1/RIMS, in Modeling Magnetospheric Plasma, vol. 44, edited by T. E. Moore and J. H. Waite Jr., p. 107, AGU, Washington, D.C., 1988.

Craven, P. D., D. L. Gallagher, and R. H. Comfort, Relative concentration of $\mathrm{He}+$ in the inner magnetosphere as observed by the DE 1 retarding ion mass spectrometer, J. Geophys. Res., 102, 2279, 1997.

Denton, R. E., J. Goldstein, J. D. Menietti, and S. L. Young, Magnetospheric electron density model inferred from Polar plasma wave data, J. Geophys. Res., 107(A11), 1386, doi:10.1029/2001JA009136, 2002.

Foster, J. C., P. J. Erickson, A. J. Coster, and J. Goldstein, Ionospheric signatures of plasmaspheric tails, Geophys. Res. Lett., 29(13), 1623, doi:10.1029/2002GL015067, 2002.

Gallagher, D. L., P. D. Craven, and R. H. Comfort, An empirical model of the Earth's plasmasphere, Adv. Space Res., 8, 15, 1988.

Goldstein, J., R. E. Denton, M. K. Hudson, E. Miftakhova, J. D. Menietti, D. Gallagher, and S. L. Young, Latitudinal density dependence along geomagnetic field lines, J. Geophys. Res., 106, 6195-6201, 2001.

Goldstein, J., R. W. Spiro, P. H. Reiff, R. A. Wolf, B. R. Sandel, J. W Freeman, and R. L. Lambour, IMF-driven overshielding electric field and the origin of the plasmaspheric shoulder of May 24, 2000, Geophys. Res. Lett., 29(16), 1819, doi:10.1029/2001GL014534, 2002.

Gringauz, K. I., The structure of the ionized gas envelope of the Earth from direct measurements in the USSR of local charged particle concentrations, Planet. Space Sci., 11, 281, 1963.

Horwitz, J. L., R. H. Comfort, and C. R. Chappell, Thermal ion composition measurements of the formation of new outer plasmasphere and double plasmapause during storm recovery phase, Geophys. Res. Lett., 11, $701,1984$.

Horwitz, J. L., R. H. Comfort, and C. R. Chappell, A statistical characterization of plasmaspheric density structure and boundary locations, J. Geophys. Res., 95, 7937, 1990a.

Horwitz, J. L., R. H. Comfort, P. G. Richards, C. M. O., C. R. Chappell, P. Anderson, W. B. Hanson, and L. H. Brace, Plasmasphere-ionosphere coupling: 2. Ion composition measurements at plasmaspheric and ionospheric altitudes and comparison with modeling results, J. Geophys. Res. 95, 7949, 1990b.

Laakso, H., and M. Jarva, Evolution of the plasmapause position, J. Atmos. Solar-Terr. Phys., 63, 1171, 2001.

LeDocq, M. J., D. A. Gurnett, and R. R. Anderson, Electron number density fluctuations near the plasmapause observed by the CRRES spacecraft, J. Geophys. Res., 99, 23,661, 1994

Lemaire, J. F., Differential drift of plasma clouds in the magnetosphere: An update, J. Atmos. Terr. Phys., 63, 1281, 2001.

Lennartsson, W., and R. D. Sharp, A comparison of the $0.1-17 \mathrm{keV} / \mathrm{e}$ ion composition in the near equatorial magnetosphere between quiet and disturbed conditions, J. Geophys. Res., 87, 6109, 1982

Meier, R. R., Ultraviolet spectroscopy and remote sensing of the upper atmosphere, Space Sci. Rev., 58, 1, 1991

Meier, R. R., and C. S. Weller, Extreme ultraviolet observations of the latitudinal variation of helium, J. Geophys. Res., 79, 1575, 1974

Meier, R. R., A. C. Nicholas, J. M. Picone, D. J. Melendez-Alvira, G. I. Ganguli, M. A. Reynolds, and E. C. Roelof, Inversion of plasmaspheric
EUV remote sensing data from the STP 72-1 satellite, J. Geophys. Res., 103, 17,505, 1998 .

Moldwin, M. B., M. F. Thomsen, S. J. Bame, D. J. McComas, and K. R. Moore, An examination of the structure and dynamics of the outer plasmasphere using multiple geosynchronous satellites, J. Geophys. Res., 99, $11,475,1994$.

Moldwin, M. B., M. F. Thomsen, S. J. Bame, D. McComas, and G. D. Reeves, The fine-scale structure of the outer plasmasphere, J. Geophys. Res., 100, 8021, 1995.

Moldwin, M. B., B. R. Sandel, M. Thomsen, and R. Elphic, Quantifying global plasmaspheric images with in situ observations, Space Sci. Rev., in press, 2002a.

Moldwin, M. B., et al., A new model of the location of the plasmapause: CRRES results, J. Geophys. Res., 107(A11), 1339, doi:10.1029/ 2001JA009211, 2002b.

Mosier, S. R., M. L. Kaiser, and L. W. Brown, Observations of noise bands asociated with the upper hybrid resonance by the IMP 6 radio astronomy experiment, J. Geophys. Res., 78, 1673, 1973.

Nakamura, M., I. Yoshikawa, A. Yamazaki, K. Shiomi, Y. Takizawa, M. Hirahara, K. Yamashita, Y. Saito, and W. Miyake, Terrestrial plasmasphere imaging by an extreme ultraviolet scanner on Planet-B, Geophys. Res. Lett., 27, 141, 2000

Nishida, A., Formation of plasmapause, or magnetospheric plasma knee, by the combined action of magnetospheric convection and plasma escape from the tail, J. Geophys. Res., 71, 5669, 1966.

Reinisch, B. W., et al., The Radio Plasma Imager investigation on the IMAGE spacecraft, Space Sci. Rev., 91, 319, 2000.

Reinisch, B. W., et al., First results from the Radio Plasma Imager on IMAGE, Geophys. Res. Lett., 28, 1167, 2001.

Sandel, B. R., et al., The extreme ultraviolet imager investigation for the IMAGE mission, Space Sci. Rev., 91, 197, 2000.

Sandel, B. R., R. A. King, W. T. Forrester, D. L. Gallagher, A. L. Broadfoot, and C. C. Curtis, Initial results from the IMAGE extreme ultraviolet imager, Geophys. Res. Lett., 28, 1439, 2001.

Swift, D. W., R. W. Smith, and S.-I. Akasofu, Imaging the Earth's magnetosphere, Planet. Space Sci., 37, 379, 1989.

Tobiska, W. K., T. Woods, F. Eparvier, R. Viereck, L. Floyd, D. Bouwer, G. Rottman, and O. R. White, The SOLAR2000 empirical solar irradiance model and forecast tool, J. Atmos. Solar-Terr. Phys., 62, 1233, 2000.

Tsyganenko, N. A., and D. P. Stern, Modeling the global magnetic field of the large-scale Birkeland current systems, J. Geophys. Res., 101, 27,187, 1996.

Weller, C. S., and R. R. Meier, First satellite observations of the $\mathrm{He}^{+} 304-\AA$ radiation and its interpretation, J. Geophys. Res., 79, 1572, 1974.

D. L. Gallagher, NASA MSFC, NSSTC, Mail Code SD50, 320 Sparkman Drive, Huntsville, AL 35805, USA. (dennis.gallagher@msfc. nasa.gov)

J. Goldstein and P. H. Reiff, Department of Physics and Astronomy, Rice University, Houston, TX 77005, USA. (jerru@rice.edu; reiff@rice.edu)

B. W. Reinisch, Center for Atmospheric Research, University of Massachusetts, Lowell, MA 01854,USA. (Bodo_Reinisch@uml.edu)

B. R. Sandel and W. T. Forrester, Lunar and Planetary Lab, University of Arizona, Tucson, AZ 85721, USA. (sandel@arizona.edu; terryf@vega. lpl.arizona.edu)

M. Spasojević, STAR Lab, Packard Building, Stanford University, Stanford, CA 94305, USA. (mssm@nova.stanford.edu) 